IZA DP No. 5230

Subjective Well-Being, Income, Economic Development and Growth

Daniel W. Sacks

Betsey Stevenson

Justin Wolfers

October 2010 


\title{
Subjective Well-Being, Income, Economic Development and Growth
}

\author{
Daniel W. Sacks \\ Wharton, University of Pennsylvania \\ Betsey Stevenson \\ Wharton, University of Pennsylvania, \\ CESifo and NBER \\ Justin Wolfers \\ Wharton, University of Pennsylvania, \\ Brookings, CEPR, CESifo, NBER and IZA
}

\author{
Discussion Paper No. 5230 \\ October 2010
}

\author{
IZA \\ P.O. Box 7240 \\ 53072 Bonn \\ Germany \\ Phone: +49-228-3894-0 \\ Fax: +49-228-3894-180 \\ E-mail: iza@iza.org
}

\begin{abstract}
Any opinions expressed here are those of the author(s) and not those of IZA. Research published in this series may include views on policy, but the institute itself takes no institutional policy positions.

The Institute for the Study of Labor (IZA) in Bonn is a local and virtual international research center and a place of communication between science, politics and business. IZA is an independent nonprofit organization supported by Deutsche Post Foundation. The center is associated with the University of Bonn and offers a stimulating research environment through its international network, workshops and conferences, data service, project support, research visits and doctoral program. IZA engages in (i) original and internationally competitive research in all fields of labor economics, (ii) development of policy concepts, and (iii) dissemination of research results and concepts to the interested public.
\end{abstract}

IZA Discussion Papers often represent preliminary work and are circulated to encourage discussion. Citation of such a paper should account for its provisional character. A revised version may be available directly from the author. 
IZA Discussion Paper No. 5230

October 2010

\section{ABSTRACT \\ Subjective Well-Being, Income, Economic Development and Growth}

We explore the relationships between subjective well-being and income, as seen across individuals within a given country, between countries in a given year, and as a country grows through time. We show that richer individuals in a given country are more satisfied with their lives than are poorer individuals, and establish that this relationship is similar in most countries around the world. Turning to the relationship between countries, we show that average life satisfaction is higher in countries with greater GDP per capita. The magnitude of the satisfaction-income gradient is roughly the same whether we compare individuals or countries, suggesting that absolute income plays an important role in influencing well-being. Finally, studying changes in satisfaction over time, we find that as countries experience economic growth, their citizens' life satisfaction typically grows, and that those countries experiencing more rapid economic growth also tend to experience more rapid growth in life satisfaction. These results together suggest that measured subjective well-being grows hand in hand with material living standards.

JEL Classification: $\quad 011,131,132$

Keywords: $\quad$ subjective well-being, life satisfaction, quality of life, economic growth, development, Easterlin Paradox, well-being-income gradient, hedonic treadmill

Corresponding author:

Justin Wolfers

Business and Public Policy Dept.

The Wharton School

University of Pennsylvania

1456 Steinberg Hall-Dietrich Hall

3620 Locust Walk

Philadelphia, PA 19104-6372

USA

E-mail: jwolfers@wharton.upenn.edu 


\section{Introduction}

Does economic growth improve the human lot? ${ }^{1}$ Using several datasets which collectively cover 140 countries and represent nearly all of the world's population, we study the relationship between subjective well-being and income, identifying three stylized facts. First, we show that within a given country, richer individuals report higher levels of life satisfaction. Second, we show that richer countries on average have higher levels of life satisfaction. Third, analyzing the time series of countries that we observe repeatedly, we show that as countries grow, their citizens report higher levels of satisfaction. Importantly, we show that the magnitude of the relationship between satisfaction and income is roughly the same across all three comparisons, which suggests that absolute income plays a large role in determining subjective well-being.

These results overturn the conventional wisdom that there is no relationship between growth and subjective well-being. In a series of influential papers, Easterlin (1973, 1995, 2005a, 2005b) has argued that economists' emphasis on growth is misguided, because he finds no statistically significant evidence of a link between a country's GDP and the subjective well-being of its citizens. This is despite the fact that Easterlin and others (e.g. Layard 1980) have found that richer individuals in a given country report higher levels of well-being. Researchers have reconciled these discordant findings, together called the Easterlin Paradox, by positing that wellbeing is determined by relative, rather than absolute, income. By this view, individuals want only to keep up with the Joneses. If true, the Easterlin Paradox suggests that focusing on economic growth is futile; when everyone grows richer, no one becomes happier. A related concern, voiced for example by Di Tella and MacCulloch (2010) is that subjective well-being

\footnotetext{
${ }^{1}$ This paper revisits—and hopefully clarifies and simplifies—many of the findings originally described in Stevenson and Wolfers (2008)
} 
adapts to circumstance. If correct, this argument implies that long run growth makes people no better off because their aspirations and expectations grow with their income. A third concern is that, even if well-being rises with income for the very poor, individuals eventually reach a satiation point, above which further income has no effect on well-being (Layard 2005). Yet in this paper, we present evidence that well-being rises with absolute income, period. This evidence suggests that relative income, adaptation and satiation are of only secondary importance.

Subjective well-being is multifaceted; it includes both how happy individuals are at a point in time and how satisfied they are with their lives as a whole (Diener 2006). In section II we briefly discuss relevant background information on the measurement of subjective wellbeing. Throughout this paper, we focus on life satisfaction, which is the variable that is both most often measured, and that has been the focus of much of the existing literature (even as economists have often referred to these satisfaction questions as measuring "happiness.") Although life satisfaction is the focus of this paper, we consider a variety of alternative measures of subjective well-being and show that they also rise with income.

In section III we demonstrate that richer individuals are more satisfied with their lives, and that this finding holds across 140 countries, and several datasets. Across each of these countries, the relationship between income and satisfaction is remarkably similar. Our graphical analysis suggests that subjective well being rises with the log of income. This functional form implies that a 20 percent rise in income has the same impact on well-being, regardless of the initial level of income: going from $\$ 500$ to $\$ 600$ of income per year yields the same impact on well-being as going from $\$ 50,000$ to $\$ 60,000$. This specification is appealing on theoretical grounds because a standard assumption in economics is that the marginal impact of a dollar of 
income is diminishing. Indeed, estimating well-being as a function of log income fits the data much better than the simple linear function of income emphasized by previous authors, and this hold whether we are making comparisons across individuals, across countries, or over time. All of our formal analyses therefore involve the log of income rather than its level, although we present scatter plots and non-parametric fitted values to allow the reader to assess the functional form for herself.

In section IV, we turn to the cross country evidence. Using larger data sets than previous authors have examined, we find an economically and statistically significant relationship between average levels of satisfaction in a country and the log of GDP per capita. The data also show no evidence of a satiation point: the same linear-log satisfaction-income gradient we observe for poor and middle-income countries holds equally well for rich countries; it does not flatten at high income.

Whereas Easterlin (1974) had argued that the relationship between well-being and income seen within countries was stronger than the relationship seen between countries, and that this provided evidence for the importance of relative income, our evidence undermines the empirical foundation for this claim. Instead, we show that the relationship between income and well-being is similar both within and between countries, thereby suggesting that absolute income plays a strong role in determining well-being, and relative income is a less important influence than had been previously believed.

In section $\mathrm{V}$ we turn to the time series evidence. While the within- and between- country comparisons cast doubt on the Easterlin Paradox, they do not by themselves tell us whether economic growth in fact translates into gains in subjective well-being. This question has challenged researchers for some time because of a lack of consistent time series data on 
subjective well-being. We analyze the time series movements in subjective well-being using two sources of comparable repeated cross-national cross-sections. Each data sets spans over two decades and covers dozens of countries.

In analyzing the time series data we can subject the relative income hypothesis to a test: if notions of a good life change as the income of one's fellow citizens grow, then we should see only a modest relationship between growth in satisfaction and growth in average income, relative to our point-in-time estimates. We present economically and statistically significant evidence of a positive relationship between economic growth and rising satisfaction over time, although limited data mean that these estimates are less precise than are those from the within- or between- country regressions. The magnitude of the estimated gradient between satisfaction and income in the time series is similar to the magnitude of the within- and between-country gradients. These results suggest that raising the income of all does indeed raise the well-being of all.

Finally, in section VI we turn to alternative measures of subjective well-being, showing that they too rise with a country's income. We find that happiness is positively related to per capita GDP across a sample of 69 countries. We then show that additional, affect-specific measures of subjective well-being, such as whether an individual felt enjoyment or love, or did not feel pain, are all higher in countries with higher per capita GDP. Our finding that subjective well-being rises with income is therefore not confined to an unusual data set or a particular indicator of subjective well-being.

Taken together, these new stylized facts suggest that subjective well-being, however measured, rises with income. Other recent papers have noted this as well. Deaton (2008) finds that individuals in richer countries have both higher levels of subjective well-being and better 
health. Stevenson and Wolfers (2008), performing an analysis parallel to this one-albeit using slightly different methods ${ }^{2}$-report similar findings to those described here, and discuss in detail why previous researchers failed to identify the strong link between subjective well-being and income.

\section{Background on Subjective Well-Being}

Subjective well-being has many facets. Some surveys, such as the World Values Survey, ask respondents about their life satisfaction, asking, “All things considered, how satisfied are you with your life these days?" The Gallup World Poll includes a variant of this question in which respondents were shown a picture and told "Here is a ladder representing the 'ladder of life.' Let's suppose the top of the ladder represents the best possible life for you; and the bottom, the worst possible life for you. On which step [between 0 and 10] of the ladder do you feel you personally stand at the present time?" This question, which we refer to as the satisfaction ladder, is a form of Cantril's "Self-Anchoring Striving Scale" (Cantril 1965). Other surveys ask about happiness directly ("Taking all things together, how would you say things are these days-would you say you're very happy, fairly happy, or not too happy?’). Gallup also asks a battery of more specific questions, ranging from "Were you proud of something you did yesterday" to "Did you experience a lot of pain yesterday?" Whereas the satisfaction question invites subjects to assess the entirety of their well-being, the more-specific questions hone in on affect; they measure feelings rather than assessments (Diener 2006). In this paper, we will largely focus on lifesatisfaction, although in section VI we turn to examining the relationship between income and particular components of well-being.

\footnotetext{
${ }^{2}$ Compared with that earlier study, some of the results in this paper differ because we consider a simpler and more transparent scaling of subjective well-being, and we use some more recent data from the Gallup World Poll.
} 
We focus on satisfaction rather than other measures of subjective well-being, such as happiness, for two reasons. First, we would like to use as many data sets as possible to assess the relationship between subjective well-being and income, and life satisfaction and the satisfaction ladder are more commonly measured than any other measure. Second, the previous literature documenting the Easterlin Paradox (including Easterlin 1974, 1995, 2005a, 2005b, 2009) has largely focused on life satisfaction questions (even as researchers have tended to label these analyses of "happiness"). Thus we focus our attention on analyzing similar questions for direct comparability with the previous literature. However, we assess the income-happiness link in detail in section VI along with other more affective measures of well-being and the results are similar to the income-satisfaction link.

Subjective well-being data are useful only if the questions succeed in measuring what they intend to measure. Economists have traditionally been skeptical of subjective data because they lack any objective anchor and because some types of subjective data, such as contingent valuations, suffer from severe biases (e.g. Diamond and Hausman 1994). These objections apply to subjective-well being data, but a variety of evidence points to a robust correlation between answers to subject-well being questions and alternative measures of personal well-being. For example, self-reported well-being is correlated with physical measures such as heart rate and electrical activity in the brain as well as sociability and a propensity to laugh and smile (Diener 1984). Self-reported well-being is also correlated with independently ascertained friends' reports and with health and sleep quality (Diener, Lucas and Scollon 2006; Kahneman and Krueger 2006). Measures of subjective well-being also tend to be relatively stable over time and they have a high test-retest correlation (Diener and Tov 2007). If people answered subjective wellbeing questions without rhyme or reason, we would not see these correlations across questions 
and people and over time. Individual subjective well-being data therefore likely are anchored by actual well-being.

Subjective well-being data lack a natural scale and are reported differently across data sets. For example happiness questions often ask respondents to choose a level of happiness from "very happy" to "very unhappy", with one or two nominal values in between. Life satisfaction can be measured on a similar scale, or on a ladder of life with ten or eleven rungs. In order to compare answers across surveys, we convert all subjective well being data into normalized variables, subtracting the sample mean and dividing by the sample standard deviation. Whenever we report the subjective well-being-income gradient, therefore, we are effectively reporting the average number of standard deviation changes in subjective well-being associated with a one unit change in income (or log income). This rescaling has the disadvantage of assuming that the difference between any two levels of life satisfaction is equal, although in fact the difference between the fifth and sixth rung on the ladder of life may be very different from the difference between the ninth and tenth. There are many alternative ways to standardize the scale of subjective well-being; Stevenson and Wolfers (2008) use an ordered probit and show that the results we discuss here are robust to alternative approaches. ${ }^{3}$

\footnotetext{
${ }^{3}$ In Stevenson and Wolfers (2008), we estimated well-being aggregates as the coefficients from an ordered probit of well-being on country fixed effects, which yielded very similar estimates. The most important difference is that the ordered probit scales differences relative to the standard deviation of well-being conditional on country dummies, while the simpler normalization in this paper scales differences relative to the (larger) unconditional standard deviation of well-being. Given that country fixed effects account for about $20 \%$ of the variation in well-being (that is, $\mathrm{R}^{2} \approx 0.2$ in an OLS regression of satisfaction on country fixed effects), this simpler normalization will tend to yield estimates of the well-being-income gradient that are about nine-tenths as large $\left(\sqrt{1-R^{2}} \approx 0.9\right)$.
} 


\section{Within-Country Estimates of the Satisfaction-Income Gradient}

We begin our study of life satisfaction and income by comparing the reported satisfaction of relatively rich and less rich individuals in a given country at a point in time. Many authors have found a positive and strong within-country relationship between subjective well being, measured in various ways, and income. For example, Robert Frank argues for the importance of income as follows: "When we plot average happiness versus average income for clusters of people in a given country at a given time ... rich people are in fact a lot happier than poor people. It's actually an astonishingly large difference. There's no one single change you can imagine that would make your life improve on the happiness scale as much as to move from the bottom 5 percent on the income scale to the top 5 percent" (Frank 2005, p. 67). We confirm this relationship, and, taking advantage of the enormous size of many of our data sets, estimate precisely the magnitude of the within-country satisfaction-income gradient.

We assess the relationship between satisfaction and income by estimating lowess regressions of satisfaction against the log of household income. Lowess regression effectively estimates a separate bivariate regression around each point in the data set, but weights nearby points most heavily (Dinardo and Tobias 2001). Traditional regression analysis imposes a linear relationship, while the lowess procedure allows researchers to study the functional form of the relationship between two variables, such as life satisfaction and the log of income.

In Figure 1, we plot the lowess estimate of the relationship between the satisfaction ladder score and the log of household income for each of the largest twenty five countries in the world (estimated separately), using data from the Gallup World Poll. ${ }^{4}$ (Analyzing income per equivalent household yields similar conclusions.) Satisfaction scores are shown both as their raw

\footnotetext{
${ }^{4}$ We are using a more recent vintage of the Gallup World Poll than Stevenson and Wolfers (2008), incorporating data made available through October 13, 2008.
} 
$(0-10)$ scores on the left axis, and in their standardized form (obtained by subtracting the whole sample mean and dividing by the standard deviation) on the right axis. To ease comparison with subsequent figures, the standardized satisfaction scale and the income scale are kept approximately constant in the various charts throughout the paper.

Figure 1 reveals the well-known finding that richer citizens of a given country are more satisfied with their life. For most countries, this plot reveals that satisfaction rises linearly with the log of income (as the horizontal axis is on a log scale). Moreover, the gradient is similar across countries, with the estimated line for each country looking like parallel shifts of each other. In spite of the enormous differences among these countries, the relationship between income and life satisfaction is remarkably similar across these countries. Finally, we note that this figure provides no evidence of satiation. While some have argued that, above a certain point, income has no impact on well-being, in these countries we see that the curve is just as steep at high levels of income as at low levels.

While these 25 countries account for the majority of the world's population, Gallup polled individuals in 132 countries, making their poll the widest survey of subjective well-being ever undertaken. We summarize and quantify the relationship between well-being and income by pooling data from all the countries in our data sets and estimating regressions of the following form:

Standardized satisfaction ic $=\sum_{\text {countries }} \alpha_{c}+\beta^{\text {individual }} \ln \left(\right.$ Income $\left._{i c}\right)+X_{i c} \delta+\varepsilon_{i c}$ where $i$ indexes individuals; $c$ indexes countries; Income is self-reported household income; and $X$ is a vector of individual-level controls including sex, a quartic in age, and their interaction. We include a country-specific intercept, $\alpha_{c}$, which adjusts for differences in average satisfaction and income across countries, thereby ensuring that the estimation results are driven by 
differences between rich and poor within each country. We denote the coefficient of interest $\beta^{\text {individual }}$ because it isolates the well-being- income gradient obtained when comparing individuals within a country. In constrast to much of the literature, we focus on the relationship between subjective well-being and the log (rather than level) of income. Our graphical evidence supports this focus, since we observe that the satisfaction-income gradient is approximately linear-log. 5

Table 1 presents the results, estimated separately in a variety of datasets. We begin by showing results from the 126 countries in the Gallup World Poll with valid income data. Next, we present results from the first four waves of the World Values Survey which spans 1980-2004 and asks respondents to assess their life satisfaction on a 1-10 scale; we pool all waves and include wave fixed effects to account for changes through time, and changes in surveys between waves. Stevenson and Wolfers (2008) document that for several countries in this survey the sampling frames are not nationally representative, and so we drop these observations from all of our analyses. Finally, we also analyze the 2002 Pew Global Attitudes Survey, which covers 44 countries at all levels of development and uses the same ladder of life question as Gallup.

The first column of Table 1 reports the regression results without any controls (beyond country fixed effects), and the estimated satisfaction-income gradient ranges from 0.216 in the World Values Survey, to 0.281 in the Pew Global Attitudes Survey. In the second column we add controls for age and sex, but our results remain similar. ${ }^{6}$ Within a given country, at a point in time, people with higher income tend to report greater life satisfaction.

\footnotetext{
${ }^{5}$ Throughout the paper, therefore, when we refer to the subjective well-being-income gradient, we mean the SWBlog income gradient.

${ }^{6}$ These estimates are slightly smaller than those found in Stevenson and Wolfers (2008), which is partly due to the different normalization of satisfaction scores, and partly due to the more recent vintage of the Gallup data analyzed here.
} 
We would like to compare the estimates from equation (1) to estimates of the crosscountry subjective well-being-income gradient, but to do so we need to have a comparable concept of income changes. While differences in income between individuals within a country reflect both transitory and permanent differences (and each has different implications for subjective well-being), income differences between countries are likely to be much more persistent, and indeed, close to entirely permanent.

How much of the cross-sectional variation in income within a country represents variation in permanent income? Standard estimates for the United States suggest that around two-fifths to a half of the cross sectional variation in annual income comes from permanent income (Haider 2001; Gottschalk and Moffit 1994). ${ }^{7}$ Our survey asks about monthly income, suggesting that the transitory share is larger; to be conservative, we simply choose the upper end of these estimates. We also need to convert the variation in transitory income into its permanent income-equivalent. If each extra dollar of transitory income persists for only one year, then people would be indifferent between one extra dollar of transitory income, and a rise in permanent income of about 5 cents (assuming a 5 percent discount rate). Estimates of the transitory component of annual income suggest that it doesn't all dissipate in one year; indeed, the autoregressive process estimated by Haider (2001) suggests that the permanent incomeequivalent of a $\$ 1$ rise in transitory income would be about twice the one-year value, or 10 cents. Consequently a one dollar increase in income in the cross section represents on average a 50 cent rise in permanent income, plus a 50 cent rise in transitory income, and this transitory income is valued equivalently to a rise in permanent income of about 5 cents. This implies that to interpret our estimated well-being-income gradient in terms of a $\$ 1$ rise in permanent income, our cross-

\footnotetext{
${ }^{7}$ While our calculations will use these U.S. estimates as if they are representative of the entire world, what is really needed is similar studies for countries at different levels of development.
} 
sectional estimates should be scaled up by about $80 \%(1 / 0.55)$. We report the adjusted estimates in the third column of Table 1, and they tend to be slightly larger than 0.4 .

We can also address this concern empirically by using an instrumental variables strategy designed to isolate variation in income that is likely permanent. Specifically, we use a full set of countryxeducation fixed effects as instruments for permanent income. The instrumental variables estimates of $\beta^{\text {individual }}$ _reported in the fourth column of Table 1 -are larger than the OLS estimates, and in the Pew and Gallup data, they are close to the estimates we obtain after making the permanent income adjustment. Education however is very likely an imperfect instrument for permanent income. While education is correlated with permanent income, it likely also directly impacts satisfaction, leading to upward bias on the instrumental variables estimates of $\beta^{\text {individual }}$. Our reading of the within-country evidence, therefore, is that the life satisfaction-log permanent income gradient falls between 0.3 and 0.5 .

We should not push these adjustments too hard, however. While it seems straightforward to think that permanent rather than transitory income determines subjective well-being, in fact direct evidence on this point suggests the opposite: subjective well-being and the business cycle move quite closely together. Stevenson and Wolfers (2008) report that the output gap strongly predicts subjective well-being, at least in the United States. Wolfers (2003) shows this also holds in Europe and across states in the United States.

\section{International Comparisons of Satisfaction and Income}

The within-country relationship between income and life satisfaction is well known and admits at least two interpretations. The first interpretation is that greater earning capacity makes people satisfied with their lives: it purchases health care; allows people to enjoy their leisure time 
with fancier food and TVs; and affords them freedom from financial stress. A second interpretation, however, is that people care less about money than about having money relative to some reference point (Easterlin 1973). One reference point is their neighbor's income, but other reference points include a country (or the world's) average income. Or perhaps people use their own previous income as a reference point. Under this view, people are stuck on a "hedonic treadmill;" as they grow richer, their expectations adapt to their circumstances, and they end up no more satisfied than they were before (Brickman and Campbell 1971). An alternative is that an "aspiration treadmill" means that even as higher income yields greater well-being, people may eventually report no higher well-being than they previously reported, because their expectations grow with their income and well-being.

To sort out these interpretations, we turn to national data. If all that matters for satisfaction is one's own income relative to one's neighbor's income, or relative to mean national income, then people in countries with high average income should be no more satisfied than people in poorer countries. Alternatively, to the extent that national differences in income reflect long-lasting differences, individuals should adapt to them (if adaptation is important), so adaptation predicts that the cross-country satisfaction-income gradient should be small. On the other hand, if absolute income matters (or if the relevant reference point is mean global income), then we would expect richer countries indeed to be more satisfied. Thus we now assess the satisfaction-income gradient across countries.

Our measure of average income in a country is GDP per capita, measured at purchasing power parity, to adjust for international differences in price levels. These data come from the World Bank's World Development indicators data base; where we are missing data, we turn to 
the Penn World Tables (version 6.2), and, failing that, the CIA Factbook. For earlier years for which data are unavailable, we turn to Maddison (2007).

Figure 2 plots average (standardized) life satisfaction data drawn from each of the first four waves of the World Values Survey, against GDP per capita (shown on a log scale). The figure shows both the OLS regression line and a non-parametric (lowess) fit. As previously noted, some of these observations were not based on nationally representative surveys (typically missing groups who might be expected to have low satisfaction), and so we plot these with squares rather than circles; they clearly lie far from the regression line (which we calculate by excluding them). ${ }^{8}$

The early waves of the survey, which contain mostly wealthy nations, provide suggestive but not overwhelming evidence for a positive link between the log of GDP per capita and subjective well-being. A researcher who mistakenly included the non-representative countries and who plotted satisfaction against the level rather than the log of income could (erroneously) fail to find a statistically significant relationship between GDP per capita and subjective wellbeing. Successive waves of the survey included more middle and low-income countries, and the relationship between income and well-being is clearer in the later waves. The four waves span 25 years and 79 distinct countries with income ranging from less than $\$ 1,000$ to over $\$ 32,000$ (in 2000 international dollars). This figure indicates a clearly positive and approximately linear-log relationship between life satisfaction and GDP.

Other data sets employing alternative measures of satisfaction show a similar positive relationship. Figure 3 plots the relationship between the satisfaction ladder scores estimated from the Pew Global Attitudes Survey and GDP per capita. The Pew data show the same pattern

\footnotetext{
${ }^{8}$ For more details about the World Values sampling frame and which country-years include nationally representative samples see Appendix B in Stevenson and Wolfers (2008)
} 
as the World Values Survey data: richer countries exhibit higher levels of satisfaction. The nonparametric fit confirms the visual impression that there are no important non-linearities: satisfaction grows with log income at about the same rate whether we focus on rich countries or poor countries. This figure provides no evidence that the satisfaction-log income gradient diminishes as income grows, suggesting that no country is rich enough to have hit a satiation point, if such a point exists.

Although the Pew and World Values Survey results provide strong evidence on the crosscountry link between satisfaction and income, neither survey has quite the global coverage the Gallup World Poll. In Figure 4, we plot the satisfaction ladder scores against per capita GDP for 131 countries included in the Gallup World Poll (we exclude Palestine, because we were unable to find reliable GDP data). Every part of the GDP distribution is well represented. This figure confirms the by-now strong impression that richer countries have higher levels of life satisfaction than poorer countries, and that this relationship is approximately linear-log. Indeed, the correlation between average satisfaction scores in a country and its log of GDP per capita is above 0.8 .

Because average well-being is rising in the log of average income, our results suggest that transferring a given amount of money from rich to poor countries could raise life satisfaction, because $\$ 100$ is a larger percentage of income in poor countries than rich countries. The linear-log relationship revealed by the non-parametric fits also provide evidence against satiation: the relationship between well-being and income does not diminish at high levels of income, except to the extent implied by the log functional form. If anything, the lowess curve appears to tick upwards even more sharply at high levels of GDP. 
We quantify the magnitude of the satisfaction-income link in by running similar regressions to equation (1), but analyzing the satisfaction of individuals $i$ in country $c$ as a function of the log of average per capita income in their country, instead of individual income (and consequently we also drop the country fixed effects):

$$
\text { Standardized satisfaction }_{i c}=\alpha+\beta^{\text {aggregate }} \ln \left(\text { GDP per capita } \text { f }_{c}\right)+X_{i c} \delta+\varepsilon_{i c}
$$

Alternatively, we aggregate our satisfaction data up into national averages, and run:

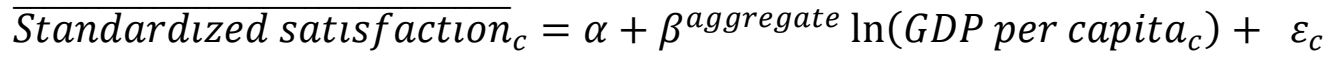

We are interested in $\beta^{\text {aggregate }}$, which says by how much average satisfaction in a country increases (in standard deviations) when the log of average per capita income in a country is higher.

These results, summarized in Table 2, confirm the impression given by the graphical analysis: all three of our data sets show a statistically significant and positive relationship between satisfaction and the log of GDP. These results suggest that absolute income plays an important role in explaining the relationship between satisfaction and income. The magnitude of the relationship is similar whether we estimate it in the individual-level data or the national averages, and whether or not we adjust for the differential age and sex composition of respondents. The coefficients on the log of average income vary somewhat but are centered on 0.3 to 0.4 .

This range is striking for its resemblance to the within-country satisfaction-income gradient. To emphasize the similarity, Figure plots data from the Gallup World Poll. Each point in the figure is a separate country, and for each country we have plotted both a dot representing the average satisfaction and income in that country, and an arrow whose slope represents the slope of the satisfaction-income gradient when comparing people within that country. As we 
look across the 126 countries with valid household income data, we find that there is no country with a statistically significantly negative relationship between satisfaction and income, and the bulk of the lines all point in similar directions, and have a similar slope. Importantly, these slopes are roughly parallel to the dashed line, which shows the slope one obtains when comparing individuals within a country is similar to that obtained when making comparisons between country averages.

That is, our estimates of the satisfaction-income gradient are similar whether estimated within or between countries. Recall that the Easterlin Paradox rested upon the belief that the well-being-income gradient observed within countries is larger than that seen between countries. Earlier estimates of a statistically insignificant cross-country relationship between average satisfaction and average income reflected the fact that previous researchers were looking at small samples of fairly homogenous countries. It was the juxtaposition of this statistically insignificant finding with evidence of a statistically significant well-being-income relationship that led Easterlin to declare the data paradoxical. But the historical absence of evidence for a proposition — that richer countries are happier—should not have been confused as being evidence of its absence. And indeed, with our larger datasets, we find statistically significant evidence that high income countries are happier than their low income counterparts. Instead, a claim about the importance of relative income comparisons should rest upon the quantitative magnitudes of the estimated well-being-income gradients.

Indeed, the similarity of the within- and between- country gradients has an important interpretation that we can express more formally. Suppose that: 


$$
\begin{aligned}
& \text { Satisfaction }_{i c}=\alpha+\beta^{\text {absolute }} \ln \left(\text { Income }_{i c}\right)+\beta^{\text {relative }} \ln \frac{\text { Income }_{i c}}{\overline{\text { Income }_{c}}} \\
& =\alpha+\left(\beta^{\text {absolute }}+\beta^{\text {relative }}\right) \ln \text { Income }_{i c}-\beta^{\text {relative }} \ln \overline{\text { Income }_{c}}
\end{aligned}
$$

where $\beta^{\text {absolute }}$ and $\beta^{\text {relative }}$ measure the importance of absolute and relative income in determining life satisfaction. Equation (1) estimates regressions of this form, regressing standardized satisfaction scores on $\ln \left(\right.$ Income $\left._{i c}\right)$ yielding a coefficient $\beta^{\text {individual }}$, and country fixed effects controlling for the influence of $\ln \overline{\operatorname{Income}_{c}}$. That is our Table 1 estimates of the within-country satisfaction-income gradient, $\beta^{\text {individual }}$ is the sum of the absolute and relative income effects: $\beta^{\text {individual }}=\beta^{\text {absolute }}+\beta^{\text {relative }}$.

Next, taking country averages of equation (4), yields:

$\overline{\text { Satlsfactlon }_{c}}=\alpha+\beta^{\text {absolute }} \ln$ Income $_{c}-\left(\beta^{\text {absolute }}+\beta^{\text {relative }}\right) M L D_{c}$

where $M L D_{c}$ (which equals $\ln \overline{\text { Income }}-\overline{\ln \text { Income }}$ ) is the mean log deviation, a measure of a country's income inequality. This equation is very similar to the cross-country estimates of equation (3), shown in Table 2. Indeed, if we had estimated $\beta^{\text {aggregate }}$ conditional on the mean $\log$ deviation, our estimate of $\beta^{\text {aggregate }}$ would give an exact estimate of $\beta^{\text {absolute }}$. Stevenson and Wolfers (2010) show that the covariance between $M L D_{c}$ and $\ln \left(G D P_{c}\right)$ is small, and so whether or not one controls for the mean log deviation has only a minimal impact on our estimate of $\beta^{\text {aggregate }}$. Our estimate of $\beta^{\text {aggregate }}$ is therefore approximately $\beta^{\text {absolute }}$. Consequently the importance of relative income in determining life satisfaction, $\beta^{\text {relative }}$, is equal to the difference $\beta^{\text {individual }}-\beta^{\text {aggregate }}$. Since we estimate that the between country gradient $\left(\beta^{\text {aggregate }}\right)$ is similar to or slightly larger than the within country gradient ( $\beta^{\text {individual }}$, we conclude that relative income plays at best a minor role in determining life satisfaction. 
An alternative story of reference-dependent preferences is based on adaptation. By this view, what matters for satisfaction is income relative to expectations, and these expectations adapt in light of recent experience. That is, economic growth simply speeds up the pace of the

hedonic treadmill, as we all run faster, just to keep in place. In turn, this implies that variation in income that has persisted for sufficiently long for expectations to adapt should be unrelated to satisfaction. The differences in log GDP per capita shown in Figures 3 through 5 are extremely persistent, and across the 131 countries in the Gallup World Poll, the correlation between the log GDP per capita in 2006 shown in Figure 4, and its value in 1980 is 0.93 . Consequently, this theory suggests that these persistent cross-country differences in GDP per capita should have little explanatory power for satisfaction. The data clearly falsify this hypothesis, too.

\section{Satisfaction and Economic Growth}

So far we have shown that richer individuals report higher life satisfaction than poorer individuals in a given country, and that on average citizens of rich countries are more satisfied with their lives than are citizens of poor countries. These comparisons suggest that absolute income plays an important role in determining well-being, but they do not directly address our central question: does economic growth improve subjective well-being?

We answer this question by turning to the time series evidence on life satisfaction and GDP, which allows us to assess whether countries that experience economic growth also experience growth in subjective well-being. Estimating the time series relationship between GDP and subjective well-being is difficult because sufficiently comparable data are rarely available. For example, the General Social Survey in the United States and the Life in Nation surveys in Japan both surveyed subjective well being over a long horizon, but both are afflicted 
by important changes in the wording and ordering of questions that, if not recognized, can lead to serious interpretation errors. Nevertheless, many scholars have found that the US has not gotten any happier over the past 35 years despite becoming wealthier, a fact that Stevenson and Wolfers (2009) note reflects a somewhat puzzling decline in female happiness. In contrast, Japan, which was once thought to have experienced little increase in happiness over the post-war period, has in fact experienced significant happiness gains that are similar in magnitude to what one would expect given the cross-sectional and cross-country relationships between subjective well-being and income. However, these happiness gains only become apparent once changes in the survey over time are taken into account (Stevenson and Wolfers 2008); the failure to take account of these changes had led many previous scholars astray (including Easterlin 1995, 2005a).

We draw on two long-running data sets to examine the relationship between subjective well-being and economic growth: the World Values Survey and the Eurobarometer. We analyze the first four waves of the World Values Survey, which span 1980 to 2004 and cover 79 distinct countries. Because the World Values Survey added many countries in later waves, however, it is not possible to make many comparisons of a given country. ${ }^{9}$ The Eurobarometer survey has the advantage that it has been surveying people in member nations of the European Union virtually continuously since 1973; however it has the disadvantage of only covering relatively homogenous countries. Unlike the other surveys, Eurobarometer ascertains life satisfaction on a four-point scale. ${ }^{10}$

Nine countries were included in the original Eurobarometer sample. Analyzing data through 1989, Easterlin (1995) concluded that the data failed to show any relationship between

\footnotetext{
${ }^{9}$ As noted earlier, some of the country samples in earlier waves of the World Values Survey are not directly comparable to later waves since their survey frames were (intentionally) not nationally representative. Our analysis focuses only on nationally representative samples.

${ }^{10}$ For the analysis, we keep West Germany and East German as separate countries. For further details on the Eurobarometer and our data procedures, see Stevenson and Wolfers (2008).
} 
life satisfaction and economic growth. In Figure 6, we present scatter plots of life satisfaction and the log of GDP per capita for the nine countries Easterlin analyzed. In the figure we include as dark circles the original data he analyzed; hollow circles denote data that have subsequently become available through to 2007 . The dark circles by themselves do not always show a strong relationship; however over the full sample, eight of the nine countries show a positive relationship between life satisfaction and growth, and six of the nine slopes are statistically significantly positive. The slopes range from -0.25 in Belgium to 0.68 in Ireland. This reanalysis not only suggests a positive relationship between income and growth, but also hints at the difficulty of isolating this relationship when data are scarce.

The positive relationship between life satisfaction and economic growth is not a feature of Europe alone. In Figure 7, we turn to the World Values Survey and plot changes in life satisfaction against cumulative changes in real GDP. This survey covers more countries, and at very different levels of development, which allows us to see whether populations become more satisfied as their countries transition from low to moderate income as well as moderate to high. To keep comparisons clean, Figure 7 excludes countries in which the sampling frame changed.

Each of the six graphs compares a different pair of waves. The top row compares short differences — the waves are separated by about five years—-while the bottom row shows longer differences of 10-20 years. All six graphs indicate a positive association between changes in subjective well-being and changes in income; the estimated gradients range from 0.22 between waves I and III to 0.71 between waves I and II. The figure shows that life satisfaction is more sensitive to short run changes in income than to long run changes, suggesting that business cycle variation may be driving some of the association. An alternative interpretation is that over time, individuals adapt to their new circumstances or their aspirations change, so that even though 
their material welfare is increasing their subjective well-being gains from these increases recede over time.

Figure 7 also reveals some potentially interesting (or problematic) outliers. Korea, for example, often falls outside the GDP change scale, but had only a modest change in subjective well-being; Hungary experienced very little growth, but had a serious decline in life satisfaction. In regression results reported below, we include these outliers, but it is clear that excluding them could change our estimates.

The comparisons in Figure 7 are particularly valuable because all the comparisons are between common pairs of waves, so they automatically adjust for the various changes in the survey_-both question order and survey techniques — that occurred between waves. Stevenson and Wolfers (2008) document that these World Values Survey data are strongly influenced by these methodological changes, so this control is important. Indeed, the influence of these changes is large enough as to render naïve comparisons of raw survey averages through time to be problematic (Easterlin and Angelscu 2009; Easterlin and Sawangfa 2008).

To distill the information from these figures into a single estimate of the intertemporal relationship between satisfaction and economic growth, we estimate panel regressions of the following form:

Satisfaction $_{t c}=\beta^{\text {time series }} \ln \left(G D P_{t c}\right)+\sum_{c \in \text { countries }} \alpha_{c}+\sum_{t \in \text { waves }} \mu_{t}+\epsilon_{t c}$

where the time fixed effects, $\mu_{t}$ control for changes in question order between waves, and the country fixed effects, $\alpha_{c}$, ensure that only within-country changes through time drive the comparisons.

Panel A of Table 3 reports the results of estimating equation (6) using the World Values Survey and the Eurobarometer. We find a substantial and statistically significant relationship 
between life satisfaction and economic growth. The estimates are not particularly precise, however, and they differ considerably between the two data sets. The satisfaction-income gradient is 0.51 in the World Values Survey and 0.17 in the Eurobarometer. In neither data set can we reject the hypothesis that the true $\beta^{\text {time series }}$ lies between 0.3 and 0.4 , the central estimate from the cross-country regressions. We can however reject the null hypothesis that $\beta^{\text {time series }}=0$, which is the outcome suggested by the view that relative rather than absolute income determines well-being.

In order to assess whether these regressions are driven by outliers, Figure 8 shows the variation underlying our World Values Survey panel regression estimates, while Figure 9 illustrates the variation underlying our Eurobarometer results. Our panel regressions reflect variation in satisfaction and log GDP per capita, stripped of country and wave fixed effects. Thus, the vertical axis shows residual satisfaction defined by Satıs $\overline{\text { factlon }}_{c t}=\overline{\text { Satlsfactlon }_{c t}}-E[\overline{\text { Satıffactlon }}$ ct $\mid$ country and wave effects $]$, which is obtained as the residual from a regression of satisfaction on country and wave fixed effects. Likewise the horizontal axis shows residual log GDP, $\ln \left(\widetilde{G D P}_{c t}\right)=\ln \left(G D P_{c t}\right)-E\left[\ln \left(G D P_{c t}\right) \mid\right.$ country and wave effects $]$, which is obtained from a similar regression in which log GDP is the dependent variable. As can be seen, when a country is experiencing relatively high levels of GDP (relative to its country average, and the estimated wave fixed effects), it also experiences high levels of satisfaction. By construction, our panel data regression coefficient in panel A of Table $3, \hat{\beta}^{\text {time series }}$, is exactly equal to the slope of the dashed bivariate regression line shown in each figure. These figures confirm that the results in Table 3 are not driven by a few outliers; the points fit the regression 
line well, and the correlation is quite strong. Equally, the data in Figure 9 paint a somewhat noisier picture for the Eurobarometer panel, although roughly similar conclusions hold.

In obtaining these estimates, however, we have drawn on all the variation in GDP in our sample, including possibly high frequency changes to which individuals do not have a chance to adapt. If adaptation occurs slowly, it would be better to focus on long run changes in GDP. Indeed, Easterlin and Angelescu (2009) argue that only long run economic growth can be used to assess the relationship between growth and well-being.

So far, only the data plotted on the bottom row of Figure 7 speak to this point, showing that even ten-year changes in GDP continue to influence life satisfaction. However, each of these comparisons is limited to the sets of countries that are common to a pair of waves. Instead, we can assess long differences for all countries by comparing changes in Satıs $\overline{f a c t}_{\text {toon }}$ and $\ln \left(\widetilde{G D P}_{c t}\right)$ between the first and last time we observe a country in the World Values Survey.

We plot these variables against each other in Figure 10 for each of the 56 countries in World Values Survey that we observe multiple times. The average difference in time between first and last observations is about eleven years. (This number is comparable to Easterlin and Sawangfa's notion of the "long run"- they require data spanning at least ten years—but somewhat lower than Easterlin and Angelescu's twelve year requirement.) The majority of countries are located in the northeast and southwest quadrants, and therefore their GDP and satisfaction moved together (relative to wave fixed effects). A notable number of countries, however, lie in the northwest and southeast; their life satisfaction and GDP move in opposite directions. Even so, the correlation between these variables is positive and remarkably strong, given that we are analyzing first differences. 
In panel B of Table 3 we report the estimate of the relationship between well-being and growth obtained from regressing these long differences in Satıs $\overline{f a c t} \iota n_{c t}$ against long differences in $\ln \left(\widetilde{G D P}_{c t}\right)$. We bootstrap our standard errors to account for the uncertainty in generating residual satisfaction and GDP. ${ }^{11}$ The coefficient is 0.47 and statistically significantly different from zero, and with these long differences, once again, we cannot reject the hypothesis that the true $\beta^{\text {time series }}$ lies between 0.3 and 0.4 .

Using these same data (although including the observations from the unrepresentative national samples and not adjusting for wave fixed effects), Easterlin and Sawangfa (2008, p.13) argue that "the positive association between the change in life satisfaction and that in GDP per capita reported by Stevenson and Wolfers rests almost entirely on the positively correlated Vshaped movement of the two variables during the post-1990 collapse and recovery in the transition countries." In order to investigate this claim, we separately estimate our panel regressions and long differences for the sample of transition countries only, and for all other World Values Survey nations. While breaking the sample apart like this reduces our statistical precision, the key inferences remain the same in both samples: the influence of GDP growth on satisfaction is positive, statistically significantly different from zero, and we cannot reject that these coefficients lie between 0.3 to 0.4 , and if anything, the World Values Survey yields estimates of the time series satisfaction-income gradient that is somewhat larger. The critique leveled by Easterlin and Sawangfa seems, quite simply, wrong.

Figure 10 provides further evidence why estimating the relationship between subjective well-being and long run growth has challenged researchers. There are indeed many countries

\footnotetext{
${ }^{11}$ We bootstrap the two-step procedure as follows. For each bootstrap iteration, we first compute the residuals as described, and then regress Satısfactıon ${ }_{c t}$ against $\ln \left(\widetilde{G D P}_{c t}\right)$. We perform 1000 iterations, and take the standard deviation of the distribution of computed gradients as our estimated standard error (after making a degrees-offreedom adjustment).
} 
which do not fit the general trend that growth in satisfaction is correlated with GDP growth. Bulgaria, the Ukraine, Venezuela, and Estonia all experienced considerable declines in income, with no accompanying decline in well-being. Furthermore, a researcher, worried about outliers, could easily drop a handful of influential countries from the sample - like Russia, Hungary, Slovenia, and Korea. Doing so clearly does not eliminate the positive correlation between these long differences, but removing these countries substantially reduces the statistical power of the regression, because these extreme cases involve so much of the variation in $\Delta \ln \left(\overline{G D P}_{c t}\right)$. When we exclude these countries from our regression of long differences, our estimate of $\beta^{\text {time series }}$ remains positive and comparable to other estimates at 0.26 , but the standard error grows to 0.15 .

We repeat this exercise using the Eurobarometer data. The advantage of these data is that we have many observations for each country, which we can combine to reduce the influence of measurement error. Thus we construct long differences in the Eurobarometer by taking averages of Satıs $\widetilde{f a c t}_{\text {fon }}$ and $\ln \left(\widetilde{G D P}_{c t}\right)$ for each country in each of the decades 1973-1982, 19831992, 1993-2002, and 2003-2007. We then construct decadal differences in satisfaction and GDP by comparing adjacent decades, and plot these decadal differences in Figure 11. Each point represents a single decadal difference in satisfaction and GDP for a given country. Many countries experienced sluggish income growth but no relative slowdown in subjective wellbeing. Most of these countries are in Western Europe. For a majority of countries, however, GDP and satisfaction do move in the same direction, although the correlation is much weaker than in our previous estimates. The estimated satisfaction-income gradient resulting from these long differences, also reported in the right column of Table 3, summarizes the results from this figure. We find a marginally statistically significant gradient of 0.28 . 
Over all we find a positive but somewhat less precise relationship between growth in subjective well-being and growth in GDP. When we use all of the time-series variation in GDP, we find a well-being-income gradient that is similar to the within-country and cross-sectional gradients. When we estimate longer differences, the precision of the relationship falls but the point estimate is similar in magnitude. This remains true whether we exclude potentially problematic "transition" economies from the sample or not, or whether we limit our attention to long-run changes in income or not, or whether we analyze data from the World Values Survey or the Eurobarometer. None of our estimates using the full variation in GDP allows us to reject the hypothesis that $\beta^{\text {time series }}$ lies between 0.3 and 0.4 , the range of our estimates of the static relationship between well-being and income.

\section{Alternative Measures of Subjective Well-Being}

Thus far, we have shown that there is a positive, statistically significant, and quantitatively important relationship between life satisfaction and income, and that this satisfaction-income gradient is similar in magnitude whether one analyzes individuals in a given country, countries at a point in time, or a given country over time. But life satisfaction is not the only measure of subjective well-being, and so we now turn to considering the relationship between various other measures of subjective well-being and income. For brevity (and also due to data availability), we will focus on cross-country comparisons of these alternative indicators.

In Figure 12 we begin by studying happiness, showing the cross-sectional relationship between happiness and the log of GDP per capita, using data from the fourth wave of the World Values Survey. We follow the same graphing conventions as in previous charts, showing the national averages as both their average on their original four point scale, and as standardized 
values (on the right axis). We also show both the regression line (where the dependent variable is the standardized measure of happiness) and the non-parametric fit; this regression line shows a positive and statistically significant relationship between happiness and per capita GDP, although the estimated happiness-income gradient is not as large as the satisfaction-income gradient we estimate in Table 2. The presence of two extreme outliers, Tanzania and Nigeria, skews the regression estimates considerably. These countries are particularly puzzling because they are the poorest in the sample, but they report among the highest levels of happiness. They also have much lower average life satisfaction—indeed, Tanzania is the least satisfied of any country in our sample. Perhaps there is a banal explanation for this puzzle: survey documentation suggests that there difficulties translating the happiness question in Tanzania. Stevenson and Wolfers (2008) discuss the happiness-income link more fully and find very similar results to the satisfaction-income link: happiness increases at any aggregation of the data, and the magnitude of the link is not much affected by the degree of aggregation.

We turn now to alternative and more specific measures of subjective well being. The Gallup World Poll asks respondents about many facets of their emotional health and daily experience. For several experiences such as enjoyment, physical pain, worry, sadness, boredom, depression, anger or love, the Gallup poll asks, "Did you experience [feeling] during a lot of the day yesterday?" These questions sketch a psychological profile of hundreds of thousands of people spanning the world's income distribution. In Figure 13, we present scatter plots of the probability that an individual in a given country experienced various emotions yesterday, against GDP per capita. The figure suggests that citizens of richer countries are more likely to experience positive emotions and less likely to experience negative emotions. Enjoyment is very highly correlated with GDP, while love is moderately correlated. Physical pain, depression, 
sadness and anger all decline moderately with GDP. ${ }^{12}$ Worry increases slightly with GDP, although there is not a strong pattern.

The Gallup poll also probes respondents for an array of sentiments about their day yesterday, asking whether they: felt well rested, were treated with respect, chose how to spend their time, if they smiled or laughed a lot, were proud of something they did, or ate good tasting food. The daily experience questions, which uniformly measure positive experiences, paint a picture that is consistent with our analysis thus far. Figure 14 shows in each country the percent of people who felt a certain way in the previous day. People in richer countries are more likely to report feeling better rested and respected, smiling more, and eating good tasting foods than people in poorer countries, although they are no more likely to take pride in what they did or to have learned something interesting.

These data point to a more nuanced relationship between well-being and income. While they give no reason to doubt that well-being rises with income, they also suggest that certain facets of well-being respond less to income than others. These data hint at the possibility of understanding which emotions and experiences translate into the part of life satisfaction that is sensitive to changes in income.

\section{Conclusions}

This paper revisits the stylized facts on the relationship between subjective well-being and income. We find that within a given country, rich individuals are more satisfied with their lives than poorer individuals, and we find that richer countries have significantly higher levels of

\footnotetext{
${ }^{12}$ See Krueger, Stevenson, and Wolfers (2010) for a more thorough exploration of the relationship between experiencing pain and income.
} 
average life satisfaction. Studying the time series relationship between satisfaction and income, we find that economic growth is associated with increases in life satisfaction.

The key innovation is this paper is to focus explicitly on the magnitude of the subjective well-being-income gradient (rather than its statistical significance), while also bringing the greatest quantity of data to bear on these questions. We show that the within-country, betweencountry, and over-time estimates all point to a quantitatively similar relationship between subjective well-being and income. This relationship is robust: we find it not only at different levels of aggregation but using different data sets. We also find that income is positively associated with other measures of subjective well-being, including happiness as well as other upbeat emotions.

The fact that life satisfaction and other measures of subjective well-being rise with income has significant implications for development economists. First, and most importantly, these findings cast doubt on the Easterlin Paradox and various theories suggesting that there is no long-term relationship between well-being and income growth. Absolute income appears to play a central role in determining subjective well-being. This conclusion suggests that economists' traditional interest in economic growth has not been misplaced. Second, our results suggest that differences in subjective well-being over time or across places likely reflect meaningful differences in actual well-being.

Subjective well-being data therefore permit cross-country well-being comparisons without reliance on price indexes. As Deaton (2010) notes, if we wish to use some kind of dollar-a-day threshold to count poverty, then we need price indices that account for differences in quality and in quantity of consumption in different countries. In theory, constructing these price indices is straightforward, provided one is ready to assume identical homothetic 
preferences across countries. In practice, however, a central challenge to creating price indices is that many countries consume very different set of goods-there is no price of smoked bonga in some countries. When countries grow richer, previously unavailable goods become traded as very expensive specialty items. Paradoxically, as a country grows richer, its poverty count can grow because its prices are revised upward, devaluing income. ${ }^{13}$

As Deaton suggests, many changes in PPP adjustments simply involve better data, and should not be ignored. But it can be difficult to know how much of the changes in the poverty count reflect actual changes in global poverty and how much reflect updating of measurement methods. In light of these difficulties, Deaton asks, "why don't we just ask people?" Using data from 87 countries spanning 2006-2008, Deaton computes average life satisfaction in each year in the world. "For the world as a whole," he writes, "2007 was a better year than 2006; in 2008 more households reported being in difficulty and being dissatisfied with their lives, and these reports were worse still in 2009” (Deaton 2010, p. 30).

Deaton notes that these comparisons are only valid if life satisfaction responds to absolute rather than relative well-being. If individuals assess their life relative to contemporary standards, then as countries and the world grow richer, reported satisfaction may not change. However, our analysis suggests an important role for absolute income in determining life satisfaction, therefore we conclude that subjective well-being data is indeed likely to be useful in assessing trends in global well-being.

Finally, we should note that we have focused on establishing the magnitude of the relationship between subjective well-being and income, rather than disentangling causality from correlation. The causal impact of income on individual or national subjective well-being, and the

\footnotetext{
${ }^{13}$ As Deaton notes, adjusting for this difficulty is in theory straightforward: weight goods by whether they are considered luxury items. This task may be quite difficult, however, because it requires making a judgment about many thousands of goods for each country in the world.
} 
mechanisms by which income raises subjective well-being, remain open and important questions. 


\section{References}

Brickman, P. and Campbell, D.T. 1990. "Hedonic Relativism and Planning the Good Society." In M.H. Appley, ed, Adaptation Level Theory: A Symposium. New York: Academic Press.

Cantrill, Hadley. 1965. The Pattern of Human Concerns. New Brunswick: Rutgers University Press.

Deaton, Angus. 2010. "Price Indexes, Inequality, and the Measurement of World Poverty." American Economic Review 100(1): 5-34.

Deaton, Angus. 2008. "Income, Health and Well-Being around the World: Evidence from the Gallup World Poll." Journal of Economic Perspectives 22(2): 53-72.

Di Tella, Rafael, and Robert MacCulloch. 2010. "Happiness Adaption to Income beyond 'Basic Needs'." In Ed Diener, John Helliwell and Daniel Kahneman, eds., International Differences in Well-Being. New York: Oxford University Press.

Diamond, Peter A, and Jerry A. Hausman. 1994. "Contingent Valuation: Is Some Number better than No Number?" Journal of Economic Perspectives 8(4): 45-64.

Diener, Ed. 2006."Guidelines for National Indicators of Subjective Well-Being and Ill-Being." Journal of Happiness Studies 7(4): 397-404.

Diener, Ed. 1984. “Subjective Well-Being.” Psychological Bulletin 95(3): 542-75.

Diener, Ed, Richard E. Lucas, and Christie Napa Scollon. 2006.”Beyond the Hedonic Treadmill: Revising the Adaptation Theory of Well-Being." American Psychologist 61(4): 305-14.

Diener, Ed, and William Tov, 2007. "Culture and Subjective Well-Being." In Shinobu Kitayama and Dov Cohen, eds., Handbook of Cultural Psychology. New York: Guilford.

Dinardo, John, and Justin L. Tobias. 2001. “Nonparametric Density and Regression Estimation,” Journal of Economic Perspectives 15(4): 11-28.

Easterlin, Richard A. 1973. "Does Money Buy Happiness?” The Public Interest 30: 3-10.

Easterlin, Richard A. 1974. "Does Economic Growth Improve the Human Lot? Some Empirical Evidence." In Paul A. David and Melvin W. Reder, eds., Nations and Households in Economic Growth: Essays in Honor of Moses Abramowitz. Academic Press.

Easterlin, Richard A. 1995. "Will Raising the Incomes of All Increase the Happiness of All?" Journal of Economic Behavior and Organization 27(1): 35-48.

Easterlin, Richard A. 2005a. "Feeding the Illusion of Growth and Happiness: A Reply to Hagerty and Veenhoven." Social Indicators Research 74(3): 429-33.

Easterlin, Richard A. 2005b. "Diminishing Marginal Utility of Income? Caveat Emptor.” Social Indicators Research 70(3): 243-55. 
Easterlin, Richard A. 2009. "Lost in Transition: Life Satisfaction on the Road to Capitalism." Journal of Economic Behavior and Organization 71(1): 130-45.

Easterlin, Richard A., and Laura Angelescu. 2009. "Happiness and Growth the World Over: Time Series Evidence on the Happiness-Income Paradox.” IZA Discussion Paper No. 4060.

Easterlin, Richard A. and Onnicha Sawangfa. 2008. "Happiness and Economic Growth: Does the Cross Section Predict Time Trends? Evidence from Developing Countries.” IZA Discussion Paper \#4000.

Frank, Robert H. 2005. “Does Absolute Income Matter?” Pier Luigi Port and Luigino Bruni, eds., Economics and Happiness: Framing the Analysis. Oxford University Press.

Gottschalk, Peter and Robert Moffit. "The Growth of Earnings Instability in the U.S. Labor Market." Brookings Papers on Economic Activity 1994(2): 217-254.

Haider, Steven J. "Earnings Instability and Earnigns Inequality of Males in the United States: 19671991." Journal of Labor Economics 19(4): 799-836.

Kahneman, Daniel, and Alan B. Krueger. 2006. "Developments in the Measurement of Subjective WellBeing." Journal of Economic Perspectives 20(1): 3-24.

Kahneman, Daniel, Alan B. Krueger, David Schkade, Norbert Schwarz, and Arthur A. Stone. 2006. "Would You Be Happier If You Were Richer? A Focusing Illusion." Science 312(5782): 1908-10.

Kruger, Alan, Betsey Stevenson and Justin Wolfers. 2010. “A World of Pain”, mimeo, University of Pennsylvania.

Layard, Richard. 1980. "Human Satisfaction and Public Policy.” Economic Journal 90(363): 737-50.

Layard, Richard. 2005. Happiness: Lessons from a New Science. London: Penguin, 2005.

Luttmer, Erzo F. P. 2005. “Neighbors as Negatives: Relative Earnings and Well-Being.” Quarterly Journal of Economics 120(3): 963-1002.

Maddison, Angus. 2007. "Historical Statistics for the World Economic: 1-2003 AD." www.ggdc.net/maddison/Historical_Statistics/horizontal-file_03-2007.xls.

Stevenson, Betsey, and Justin Wolfers. 2008. "Economic Growth and Subjective Well-Being: Reassessing the Easterlin Paradox.” Brookings Papers on Economic Activity 2008(1): 1-87.

Stevenson, Betsey and Justin Wolfers. 2009. "The Paradox of Declining Female Happiness." American Economic Journal: Economic Policy 1(2):190-225.

Stevenson, Betsey and Justin Wolfers. 2010. Inequality and Subjective Well-Being. Working paper.

Wolfers, Justin. 2003. "Is Business Cycle Volatility Costly? Evidence from Surveys of Subjective WellBeing” International Finance 6(1): 1-26. 


\section{Table 1: Within-Country Satisfaction-Income Gradient}

\begin{tabular}{|c|c|c|c|c|c|}
\hline $\begin{array}{l}\text { Dependent variable: } \\
\text { Standardized Life satisfaction }\end{array}$ & $\begin{array}{l}\text { Without } \\
\text { controls }\end{array}$ & $\begin{array}{l}\text { With } \\
\text { controls }\end{array}$ & $\begin{array}{l}\text { Permanent Income } \\
\text { Adjusted }\end{array}$ & $\begin{array}{l}\text { Instrumental } \\
\text { Variables }\end{array}$ & Sample size \\
\hline $\begin{array}{l}\text { Gallup World Poll: Ladder } \\
\text { question }\end{array}$ & $\begin{array}{l}0.236^{\text {***\% }} \\
(0.014)\end{array}$ & $\begin{array}{l}0.232^{* * * *} \\
(0.014)\end{array}$ & 0.422 & $\begin{array}{l}0.449^{* * * *} \\
(0.027)\end{array}$ & $\begin{array}{r}171,900 \\
(126 \text { Countries) }\end{array}$ \\
\hline $\begin{array}{l}\text { World Values Survey: } \\
\text { Life satisfaction }\end{array}$ & $\begin{array}{l}0.216^{* * *} \\
(0.017)\end{array}$ & $\begin{array}{l}0.227^{* * * *} \\
(0.037)\end{array}$ & 0.413 & $\begin{array}{l}0.26^{* * *} \\
(0.035)\end{array}$ & $\begin{array}{r}116,527 \\
(61 \text { Countries })\end{array}$ \\
\hline $\begin{array}{l}\text { Pew Global Attitudes Survey: } \\
\text { Ladder question }\end{array}$ & $\begin{array}{l}0.281^{* * *} \\
(0.027)\end{array}$ & $\begin{array}{l}0.283^{* * *} \\
(0.027)\end{array}$ & 0.515 & $\begin{array}{l}0.393^{* * *} \\
(0.033)\end{array}$ & $\begin{array}{r}32,463 \\
\text { (43 Countries) }\end{array}$ \\
\hline
\end{tabular}

Notes: The table reports the coefficient on the log of household income, obtained from regressing standardized life satisfaction against the log of household income and country fixed effects using the indicated data set. Additional controls include a quartic in age, interacted with sex, plus indicators for age and sex missing. Our permanent income adjustment is to scale up our estimates by $1 / 0.55$; see text for explanation. We instrument for income using full set of countryxeducation fixed effects. We report robust standard errors, clustered at the country level, in parentheses. For further details on the standardization of satisfaction and the exact wording of satisfaction question, see the text. ${ }^{* * *}, * *$ and ${ }^{*}$ denote statistically significant at $1 \%, 5 \%$ and $10 \%$, respectively. 
Table 2: Cross-Country Regressions of Life Satisfaction on Log GDP per Capita ${ }^{\mathrm{a}}$

\begin{tabular}{|c|c|c|c|c|}
\hline \multirow[b]{2}{*}{$\begin{array}{l}\text { Dependent variable: } \\
\text { Standardized life satisfaction }\end{array}$} & \multicolumn{2}{|c|}{ Microdata } & \multirow[t]{2}{*}{ National Data } & \multirow[b]{2}{*}{ Sample size } \\
\hline & $\begin{array}{l}\text { Without } \\
\text { controls }\end{array}$ & $\begin{array}{l}\text { With } \\
\text { controls }\end{array}$ & & \\
\hline $\begin{array}{l}\text { Gallup World Poll: Ladder } \\
\text { question }\end{array}$ & $\begin{array}{c}0.357^{* * *} \\
(0.019)\end{array}$ & $\begin{array}{l}0.378^{* * * *} \\
(0.019)\end{array}$ & $\begin{array}{l}0.342^{* * * * *} \\
(0.019)\end{array}$ & $\begin{array}{r}291,383 \\
\text { (131 countries) }\end{array}$ \\
\hline $\begin{array}{l}\text { World Values Survey: } \\
\text { Life satisfaction }\end{array}$ & $\begin{array}{l}0.360^{* * *} \\
(0.034)\end{array}$ & $\begin{array}{l}0.364^{* * *} \\
(0.034)\end{array}$ & $\begin{array}{l}0.370^{* * *} \\
(0.036)\end{array}$ & $\begin{array}{r}234,093 \\
(79 \text { countries })\end{array}$ \\
\hline $\begin{array}{l}\text { Pew Global Attitudes } \\
\text { Survey: Ladder question }\end{array}$ & $\begin{array}{l}0.214^{\text {**** }} \\
(0.039)\end{array}$ & $\begin{array}{l}0.231^{* * * *} \\
(0.038)\end{array}$ & $\begin{array}{l}0.204^{* * *} \\
(0.037)\end{array}$ & $\begin{array}{r}37,974 \\
(44 \text { countries })\end{array}$ \\
\hline
\end{tabular}

Notes: The table reports the coefficient on the log of per capita GDP, obtained from regressing standardized life satisfaction against the log of GDP, using individual data with and without controls, and using national-level data without controls, in the indicated data set. In the national-level regressions, we take the within-country average of standardized life satisfaction as the dependent variable. GDP per capita is at purchasing power parity. The additional controls include a quartic in age, interacted with sex, plus indicators for age and sex missing. We report robust standard errors, clustered at the country level, in parentheses. For further details on the standardization of satisfaction, the exact wording of satisfaction question, and the sources for GDP per capita, see the text. ${ }^{* * *},{ }^{* *}$ and ${ }^{*}$ denote statistically significant at $1 \%, 5 \%$ and $10 \%$, respectively. 
Table 3: Time Series Regressions of Life Satisfaction on GDP per Capita ${ }^{a}$

\begin{tabular}{|c|c|c|c|c|}
\hline $\begin{array}{l}\text { Dependent variable: } \\
\text { Standardized life } \\
\text { satisfaction }\end{array}$ & $\begin{array}{l}\text { WVS: } \\
\text { All Countries }\end{array}$ & $\begin{array}{l}\text { WVS: } \\
\text { Transition } \\
\text { Countries }\end{array}$ & $\begin{array}{l}\text { WVS: } \\
\text { Non-transition } \\
\text { Countries }\end{array}$ & $\begin{array}{l}\text { Eurobarometer: } \\
\text { All Countries }\end{array}$ \\
\hline \multicolumn{5}{|c|}{ Panel A: Panel Regressions } \\
\hline $\ln ($ GDP) & $\begin{array}{l}0.505^{* * *} \\
(0.109)\end{array}$ & $\begin{array}{c}0.628^{* * *} \\
(0.239)\end{array}$ & $\begin{array}{l}0.407^{* * * *} \\
(0.116)\end{array}$ & $\begin{array}{l}0.17^{* *} \\
(0.074)\end{array}$ \\
\hline $\mathrm{N}$ & $\begin{array}{r}166 \text { observations } \\
79 \text { countries }\end{array}$ & $\begin{array}{r}31 \text { observations } \\
10 \text { countries }\end{array}$ & $\begin{array}{r}135 \text { observations } \\
66 \text { countries }\end{array}$ & $\begin{array}{r}776 \text { observations } \\
31 \text { countries }\end{array}$ \\
\hline \multicolumn{5}{|c|}{ Panel B: Long differences } \\
\hline $\ln ($ GDP) & $\begin{array}{c}0.47^{* * * *} \\
(0.128)\end{array}$ & $\begin{array}{c}0.694^{*} \\
(0.387)\end{array}$ & $\begin{array}{l}0.35^{* *} \\
(0.163)\end{array}$ & $\begin{array}{c}0.278^{*} \\
(0.164)\end{array}$ \\
\hline $\mathrm{N}$ & 66 differences & 10 differences & 46 differences & 30 differences \\
\hline
\end{tabular}

Notes: The table reports the coefficient on the log of GDP per capita. In the panel regressions, we regress standardized life satisfaction against the log of GDP per capita as well as wave and country fixed effects. In the long differences, we regress the change in standardized satisfaction against the change in log GDP per capita, after adjusting satisfaction and log GDP for wave and country fixed effects. Long differences in the World Values Survey are taken between the first and last time we see a country; in the Eurobarometer, between decadal averages. We report robust standard errors, clustered at the country level, in parentheses. For further details on the standardization of satisfaction, the exact wording of satisfaction question, the sources for GDP per capita, the procedure used to compute long differences, and the definition of transition countries, see the text. . ${ }^{* * * *},{ }^{* *}$ and ${ }^{*}$ denote statistically significant at $1 \%, 5 \%$ and $10 \%$, respectively. 
Figure 1: Relationship Between Well-being and Income, Within Individual Countries, Gallup World Poll

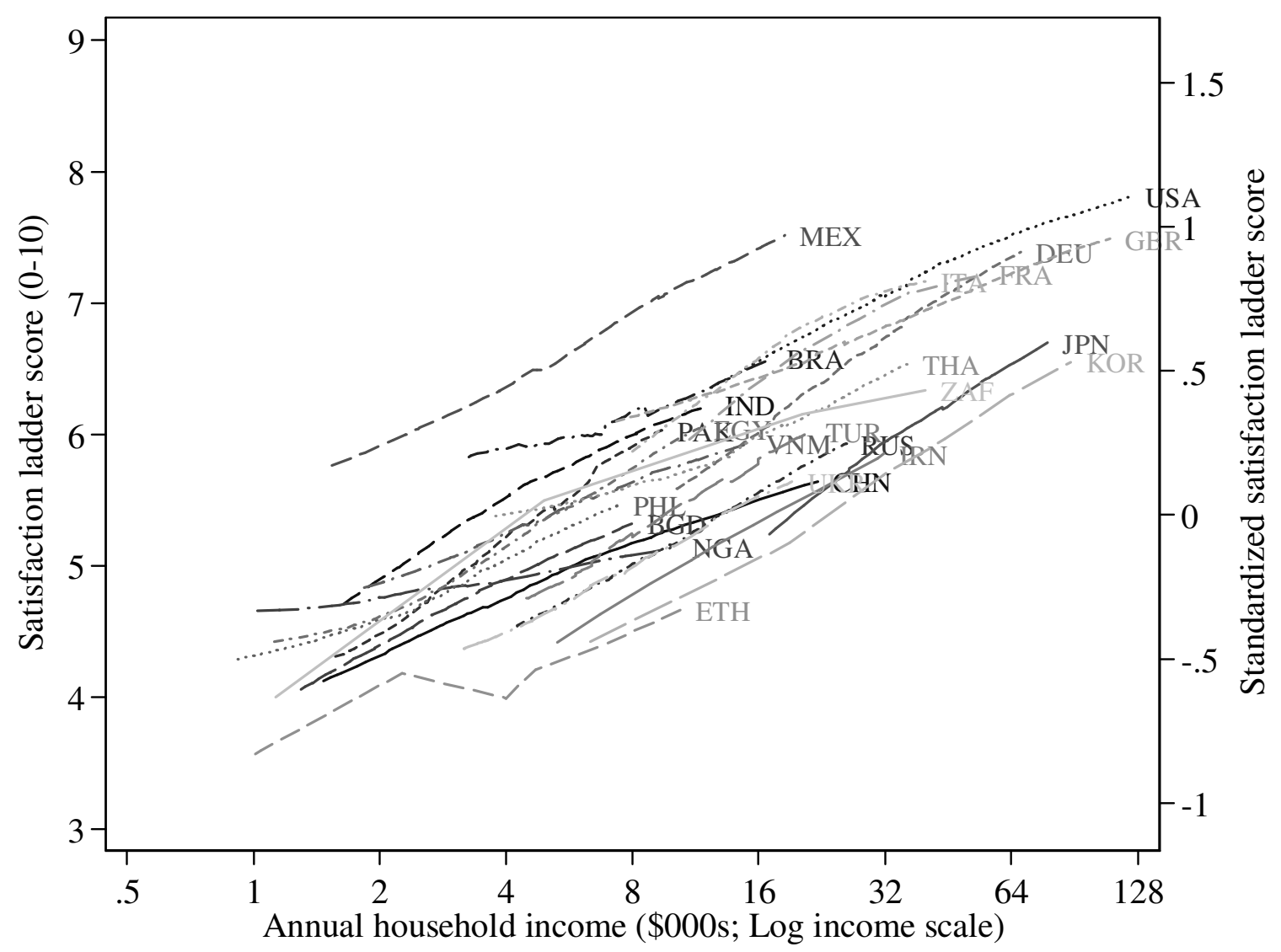

Notes: The figure shows, for the 25 largest countries, the lowess fit between individual satisfaction ladder scores and the log of household income, measured in the Gallup World Poll. The satisfaction data are shown both on their raw $(0-10)$ scale on the left axis, and as standardized variables on the right axis. We plot the lowess fit between the 10th and 90th percentiles of each country's income distribution. Satisfaction is assessed using the ladder of life question. 


\section{Figure 2: Life Satisfaction and Real GDP per Capita, World Values Survey}

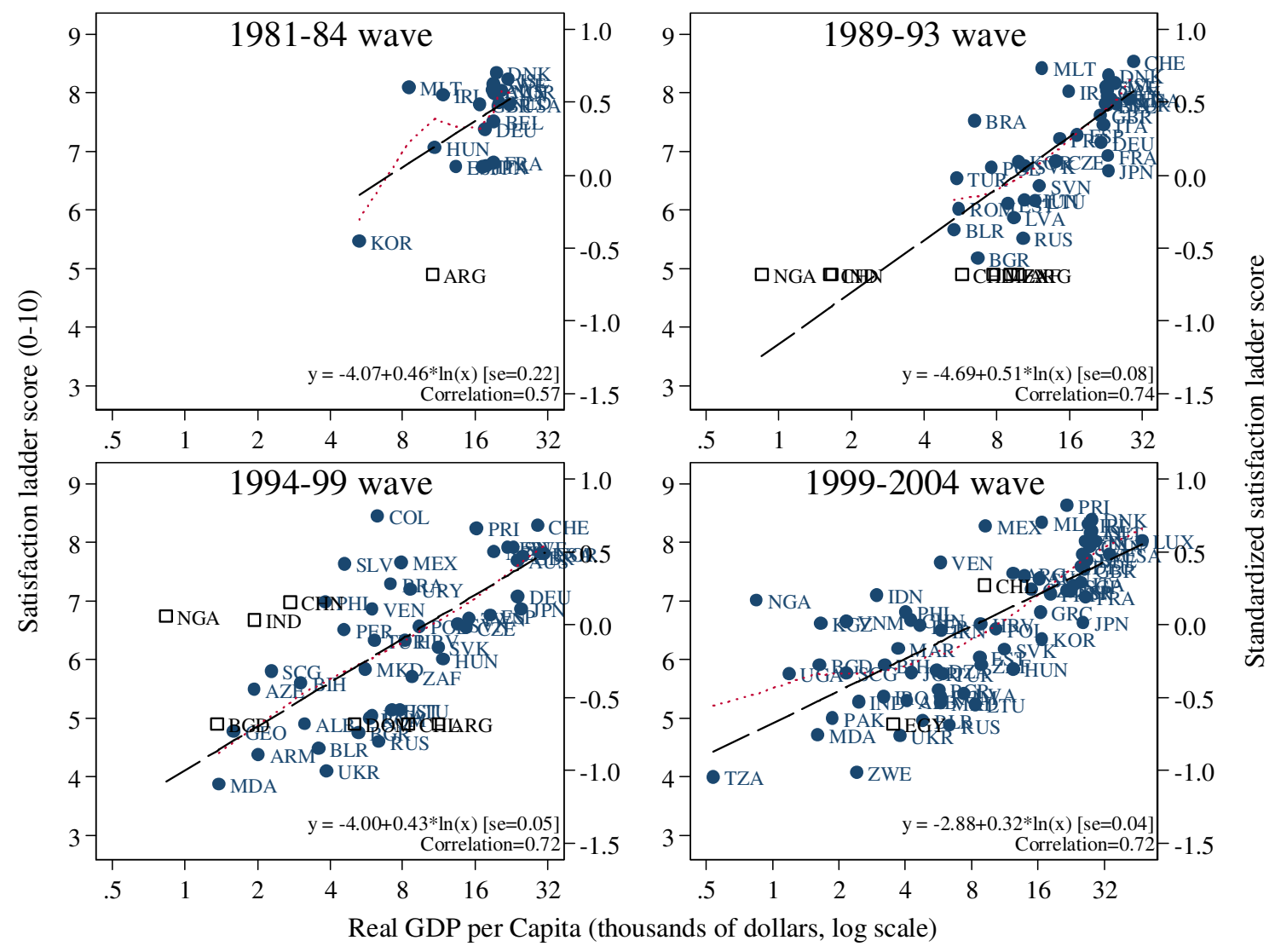

Notes: Respondents are asked, "All things considered, how satisfied are you with your life as a whole these days?"; respondents then choose a number from 1 (completely dissatisfied) to 10 (completely satisfied). Data are aggregated by first standardizing individual-level data to have mean zero and unit standard deviation, and then taking country-year averages of the standardized values. The left axis gives the raw average satisfaction and the right axis gives the standardized satisfaction. Dashed lines are fitted from an OLS regression; dotted lines are fitted from lowess regressions. These lines and the reported regressions are fitted only from the nationally representative samples. The units on the regression coefficients refer to the normalized scale. Real GDP per capita is at purchasing power parity in constant 2000 international dollars. Sample includes 20 (1981-84) 42 (1989-93), 52 (1984-99) or 69 countries (1999-2004) from the World Values Survey. Observations represented by hollow squares are drawn from countries in which the World Values Survey sample is not nationally representative (see Stevenson and Wolfers (2008), appendix B, for more details). 


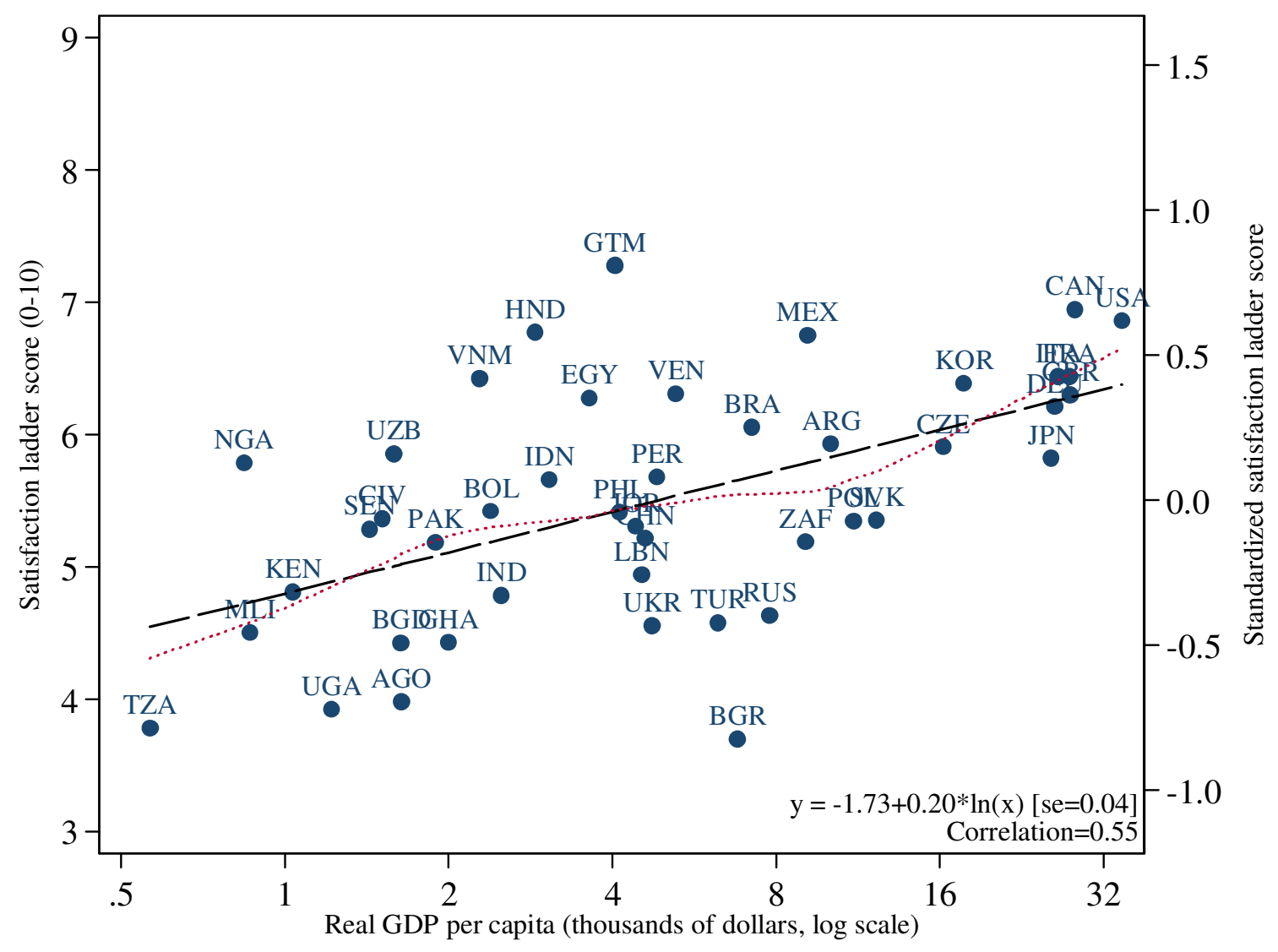

Notes: Respondents are shown a picture of a ladder with ten steps and asked, "Here is a ladder representing the 'ladder of life.' Let's suppose the top of the ladder represents the best possible life for you; and the bottom, the worst possible life for you. On which step of the ladder do you feel you personally stand at the present time?" Data are aggregated by first standardizing individual-level data to have mean zero and unit standard deviation, and then taking country-year averages of the standardized values. The left axis gives the raw average satisfaction and the right axis gives the standardized satisfaction score. Dashed lines are fitted from an OLS regression; dotted lines are fitted from lowess regressions. Regression coefficients are in terms of the standardized scaling. Real GDP per capita is at purchasing power parity in constant 2000 international dollars. Sample includes forty-four developed and developing countries. 
Figure 4: Life Satisfaction and Real GDP per Capita, Gallup World Poll

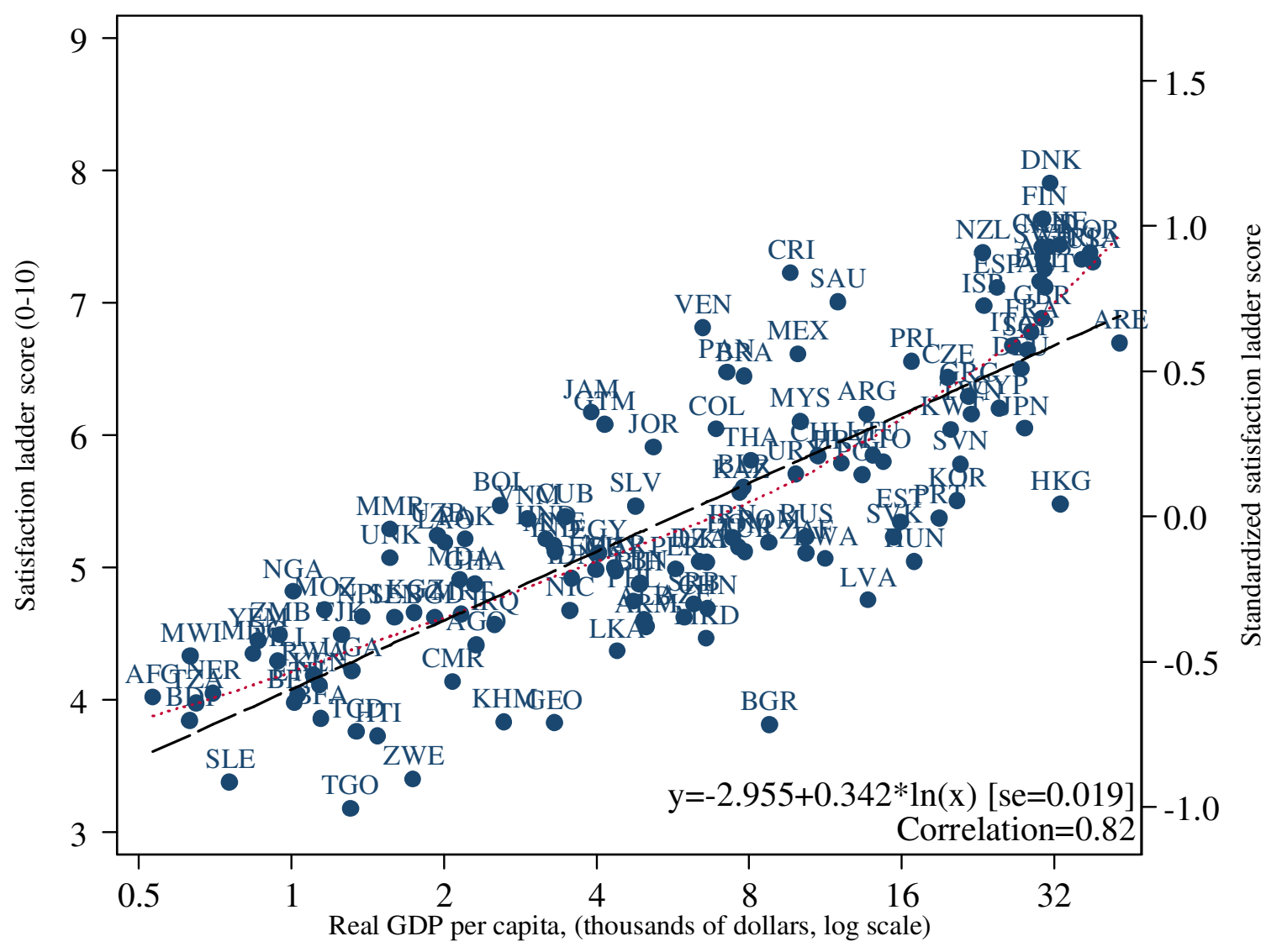

Notes: Respondents are shown a picture of a ladder with ten steps and asked, "Here is a ladder representing the 'ladder of life.' Let's suppose the top of the ladder represents the best possible life for you; and the bottom, the worst possible life for you. On which step of the ladder do you feel you personally stand at the present time?" Data are aggregated by first standardizing individual-level data to have mean zero and unit standard deviation, and then taking country-year averages of the standardized values. Dashed lines are fitted from an OLS regression; dotted lines are fitted from lowess regressions. The units on the regression coefficients refer to the normalized scale. Real GDP per capita is at purchasing power parity in constant 2000 international dollars. Sample includes 131 developed and developing countries. 
Figure 5: Within-Country and Between-Country Estimates of the Life SatisfactionIncome Gradient, Gallup World Poll

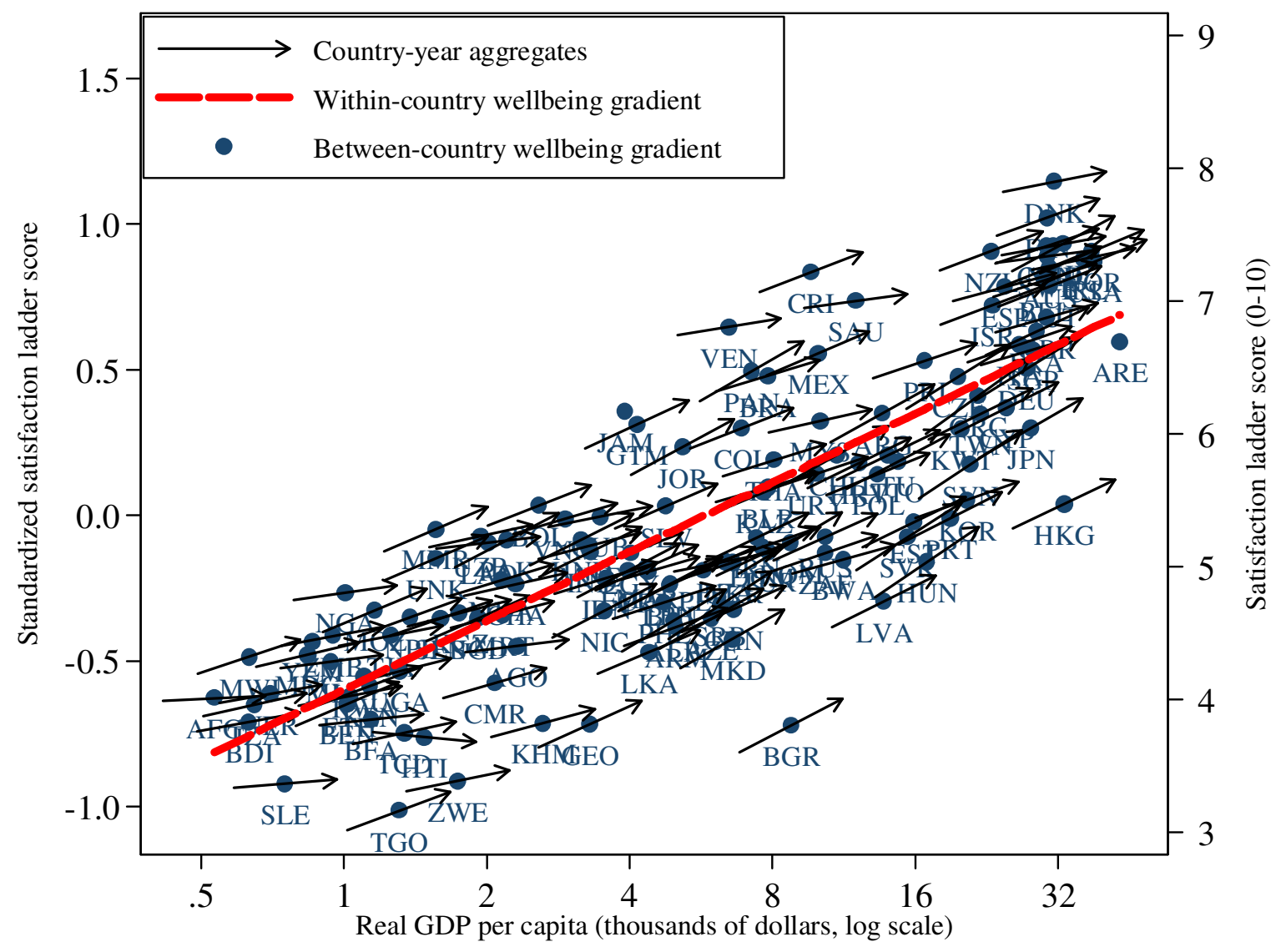

Notes: Each solid circle plots life satisfaction against GDP per capita for one of 131 developed and developing countries. The slope of the arrow represents the satisfaction-income gradient estimated for that country from a country-specific regression of individual standardized satisfaction on the log of their annual real household income, controlling for gender, a quartic in age, and their interaction. Usable household income data were unavailable for eighteen countries. The dashed line represents the between-country satisfaction-income gradient estimated from an OLS regression of the satisfaction index on the log of real GDP per capita. GDP per capita is at purchasing power parity in constant 2000 international dollars. 


\section{Figure 6: Changes in Life Satisfaction and Economic Growth in Europe, Eurobarometer Survey}

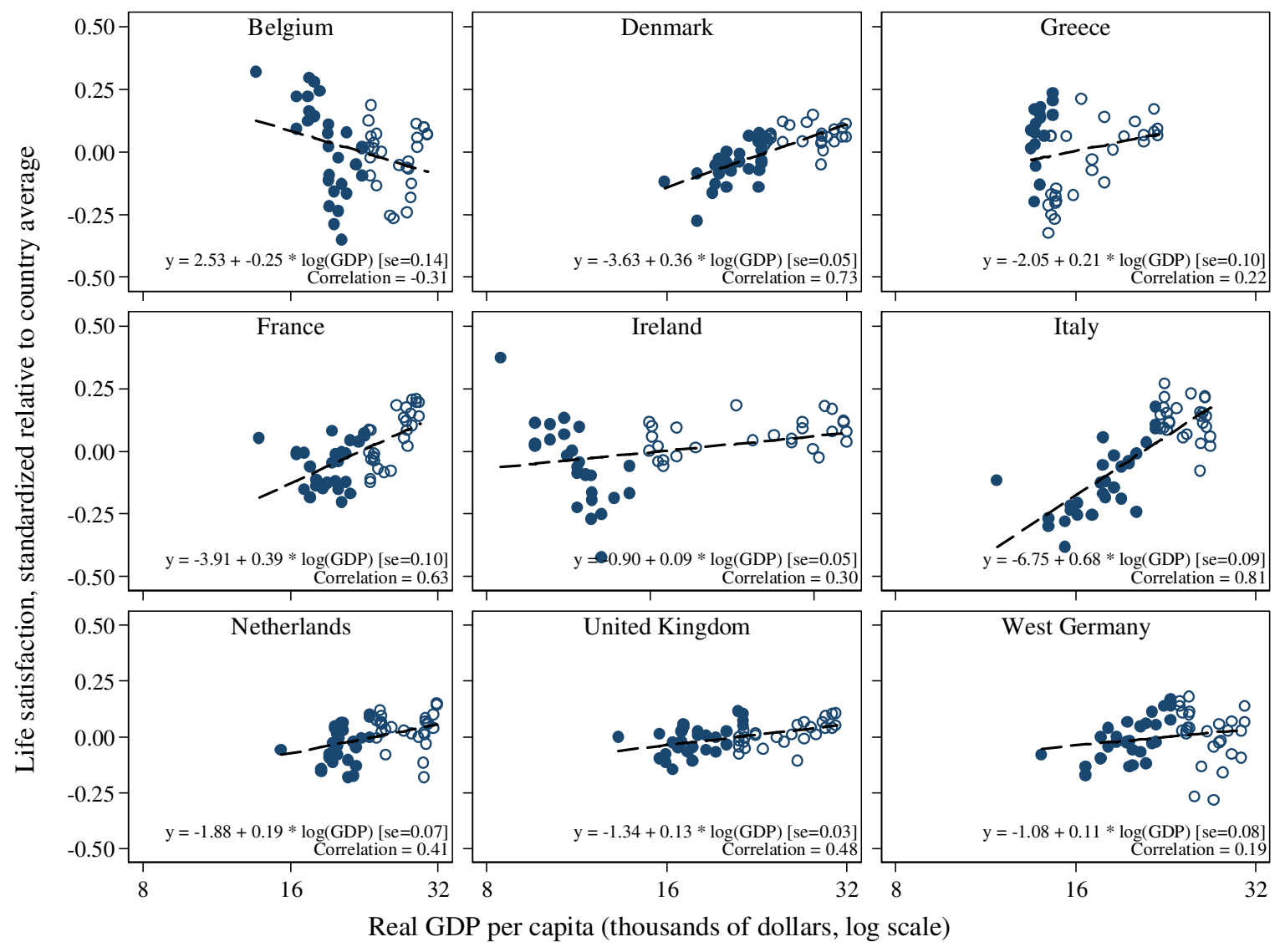

Notes: Solid circles represent separate observations from each round of the Eurobarometer survey from 1973 to 1989; these were the data analyzed in Easterlin (1995); open circles extend the sample from 1990 to 2002 using the Eurobarometer Trendfile, and then through to 2007 using biannual Eurobarometer reports. Each panel shows data for one of the nine countries analyzed by Easterlin (1995). Data are aggregated by first standardizing individuallevel data to have mean zero and unit standard deviation, and then taking country-year averages of the standardized values. Dashed lines are fitted from the reported OLS regression; Newey-West standard errors (se) are reported, accounting for first-order autocorrelation. The life satisfaction question asks, "On the whole, are you very satisfied, fairly satisfied, not very satisfied, or not at all satisfied with the life you lead?" GDP per capita is at purchasing power parity in constant 2000 international dollars. 


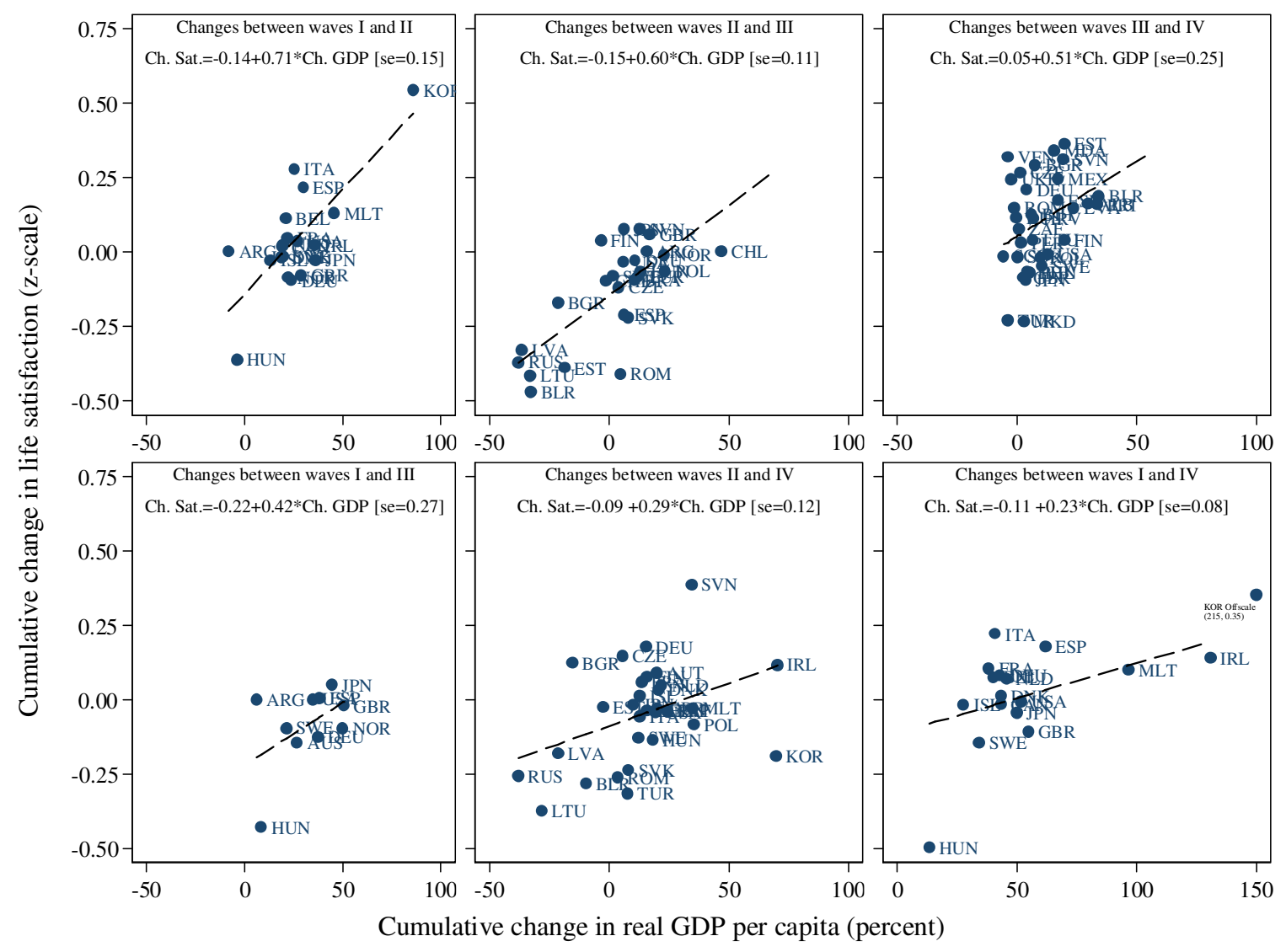

Notes: We restrict the sample in each graph to countries in which the WVS sample that did not change sampling frames between the given waves. Each point gives the change in life satisfaction and real GDP for a given country and a given pair of waves. Data are aggregated by first standardizing individual-level data to have mean zero and unit standard deviation, and then taking country-year averages of the standardized values. The dashed lines give the OLS fit. Graphs in the first row show nineteen, ten, and seventeen comparable short first differences, and those in the second row twenty-five, thirty-two and thirty-three long first differences. GDP per capita is at purchasing power parity in constant 2000 international dollars. 
Figure 8: Life Satisfaction and Log GDP, Relative to Country and Year Fixed Effects, World Values Survey

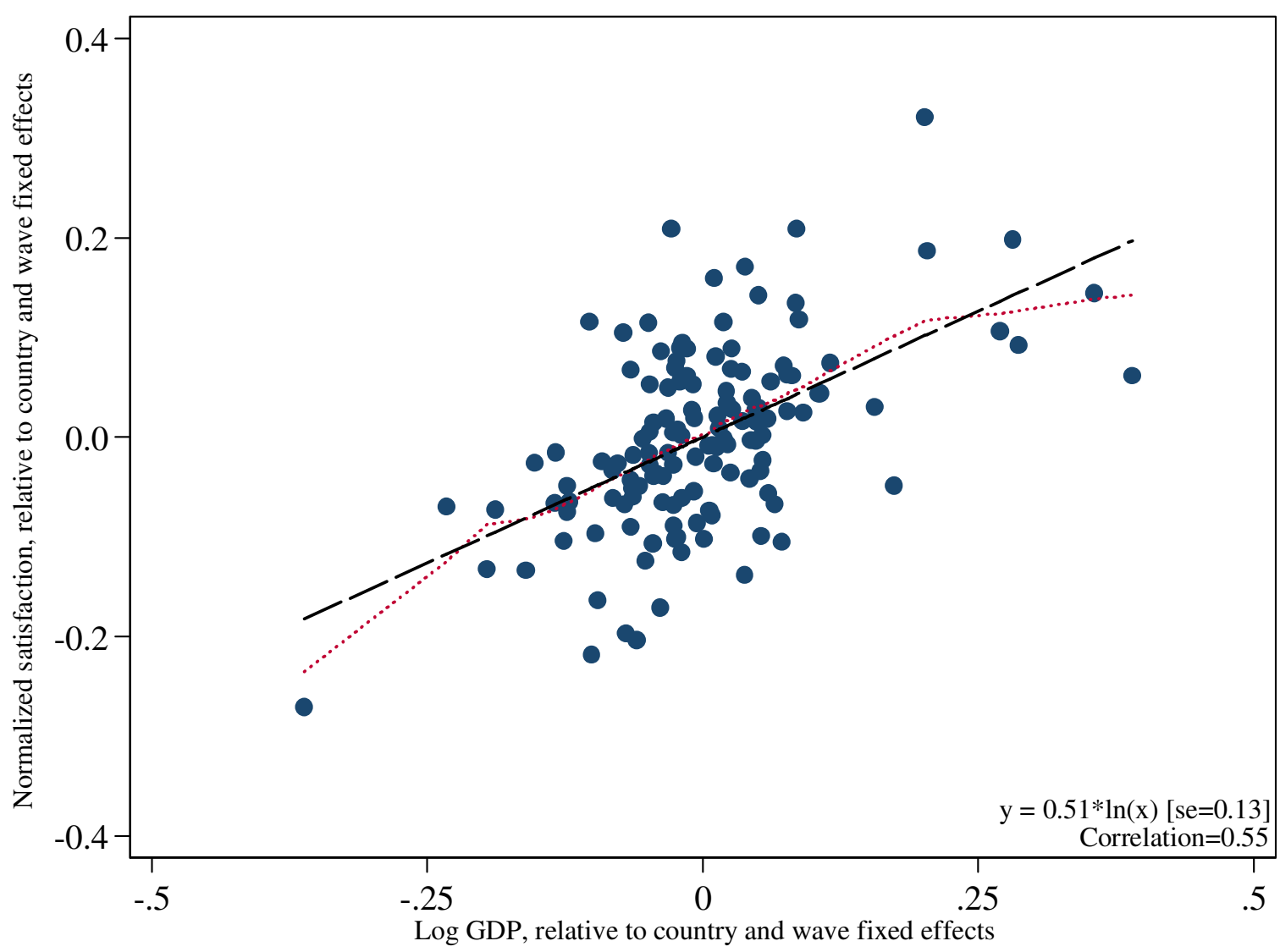

Notes: We plot residuals from a regression of log GDP or normalized average satisfaction against country and wave fixed effects, using all four waves of the World Values and excluding countries for which the sampling frame is not nationally representative. Data were aggregated by first standardizing individual-level data to have mean zero and unit standard deviation, and then taking country-year averages of the standardized values. The dashed line gives the OLS fit and the dotted line is fitted from lowess regression. For further details, see text. 
Figure 9: Life Satisfaction and Log GDP, Relative to Country and Year Fixed Effects, Eurobarometer

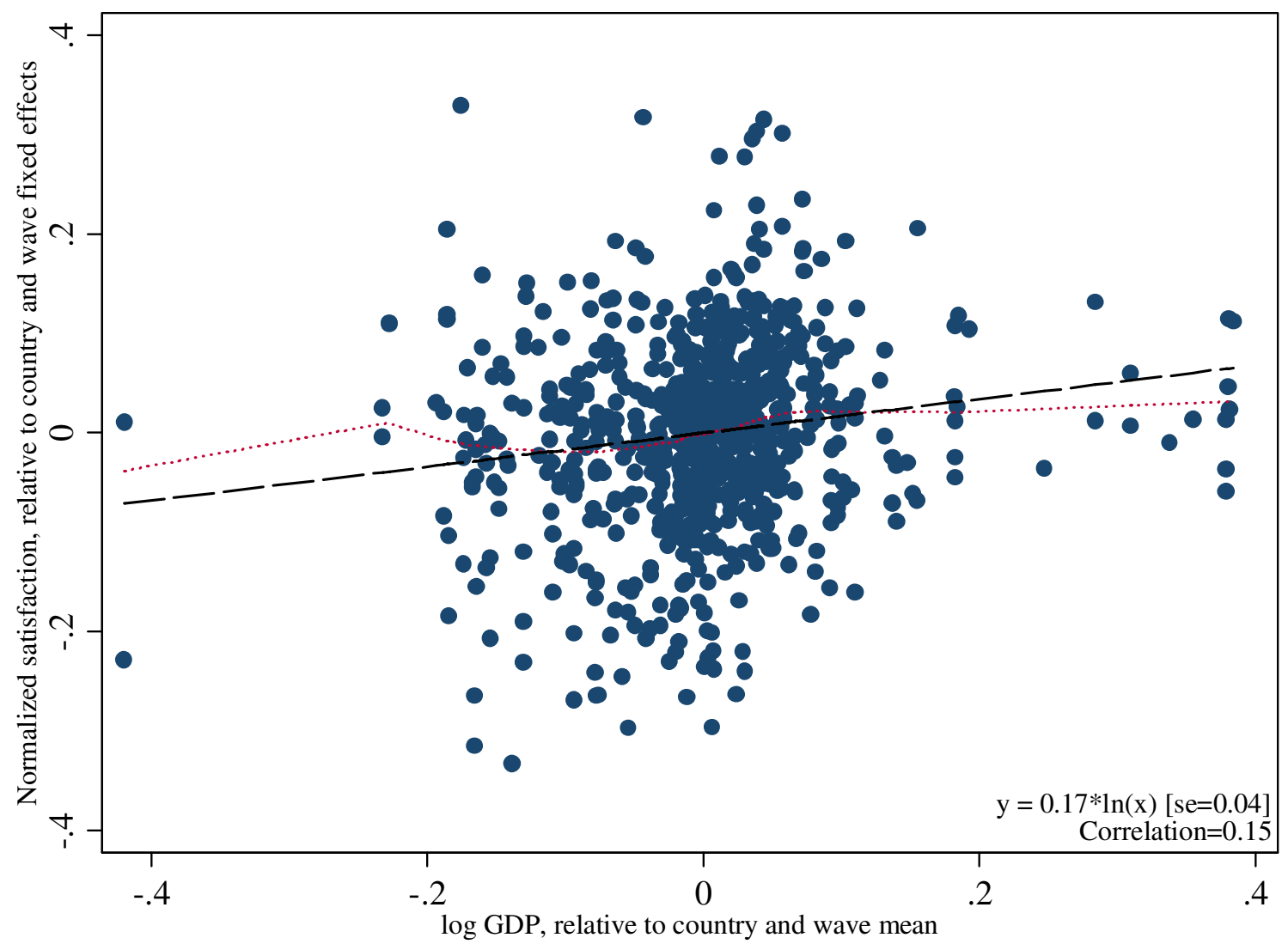

Notes: We plot residuals from a regression of log GDP or normalized average satisfaction against country and wave fixed effects. Data were first aggregated by first standardizing individual-level data to have mean zero and unit standard deviation, and then taking country-year averages of the standardized values. The dashed line gives the OLS fit and the dotted line is fitted from lowess regression. 
Figure 10: Long Differences in Life Satisfaction and Log GDP, World Values Survey

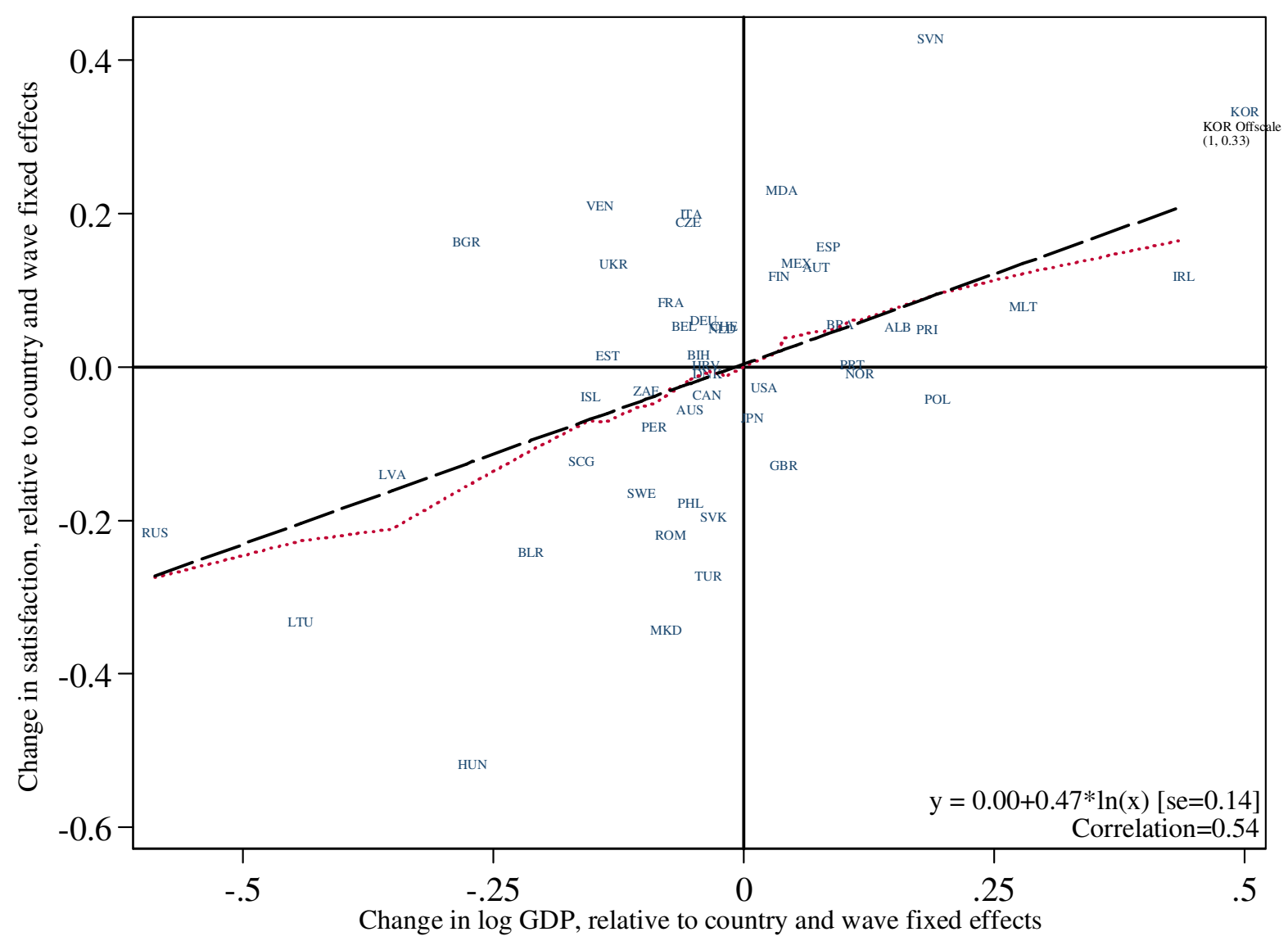

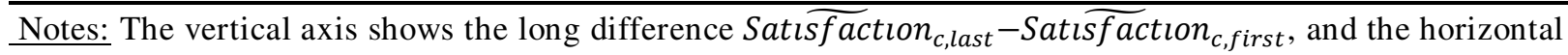
axis shows the long difference $\ln \widetilde{(G D P})_{c, l a s t}-\ln (\overline{G D P})_{c, f i r s t}$ where the subscripts denote the first and last time each country was observed in the four waves of the World Values Survey. The variables Satı $\widetilde{s f a c t ı o n}$ ct and $\ln (\overline{G D P})_{c t}$ reflect the residuals estimated after regressing Satis faction $_{c t}$ and $\ln (G D P)_{c t}$ (respectively) on country and wave fixed effects. We use all four waves of the World Values and excluding countries for which the sampling frame is not nationally representative. Data are aggregated by first standardizing individual-level data to have mean zero and unit standard deviation, and then taking country-year averages of the standardized values. The dashed line gives the OLS fit and the dotted line is fitted from lowess regression. For further details, see text. 
Figure 11: Decadal Differences in Life Satisfaction and Log GDP, Eurobarometer

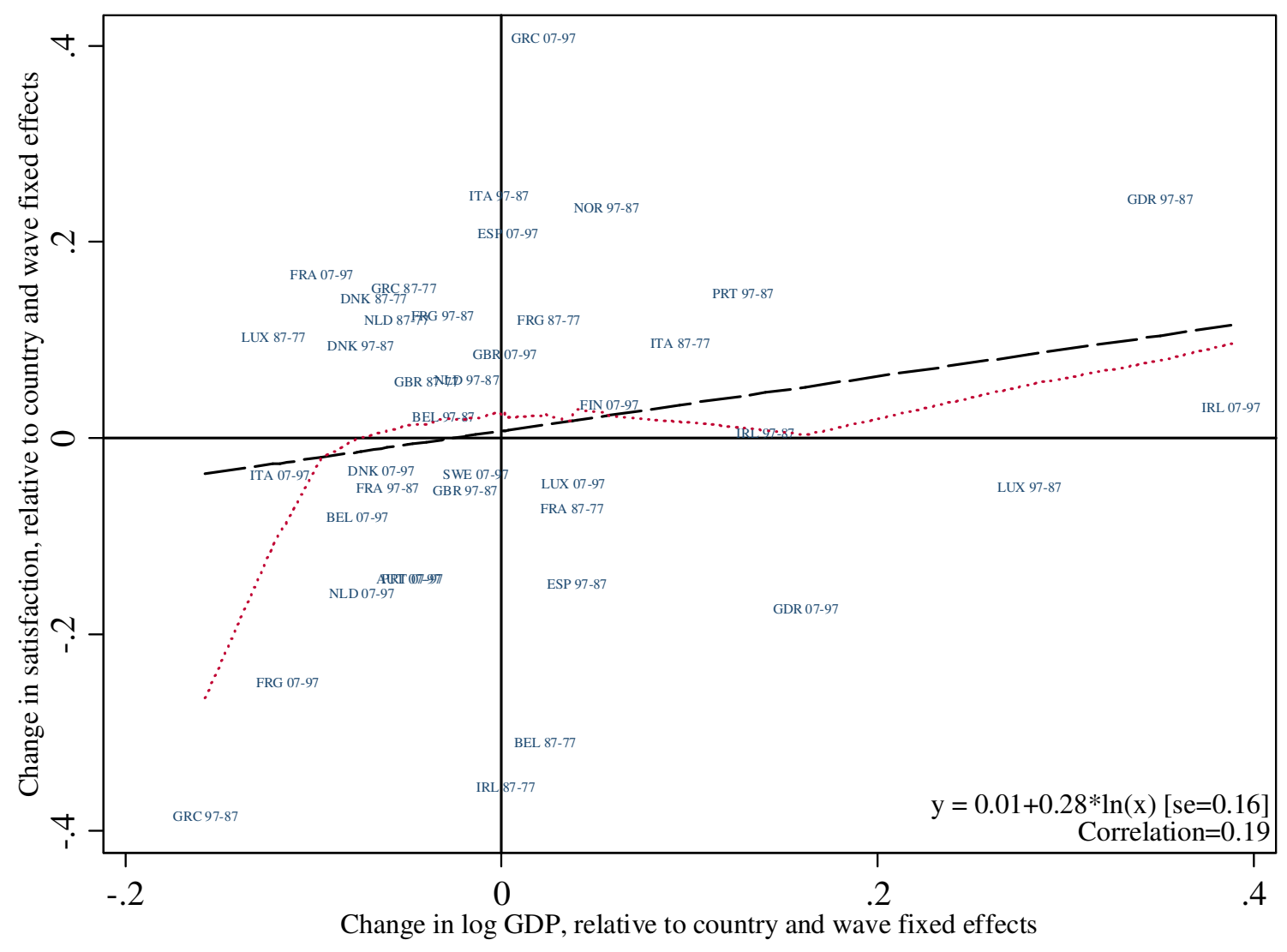

Notes: Eurobarometer 1973-2007; sources for GDP per capita described in text. The vertical axis shows the long differences Satısfactıon ${ }_{c, d}-$ Satısfactlon $_{c, d-1}$, and the horizontal axis shows the long difference $\left.\ln \widetilde{(G D P})_{c, d}-\ln \widetilde{(G D P}\right)_{c, d-1}$ where Satısfactıon ${ }_{c, d}$ and $\left.\ln \widetilde{(G D P}\right)_{c, d}$ are, respectively, decadal averages of Satısfactıon ${ }_{c, t}$ and $\widetilde{\log G D} P_{c, t}$, taken over the decades 1973-82; 1983-92; 1993-02 and the partial decade, 2003-07. The variables Satısfactıon $n_{c t}$ and $\widetilde{\ln G D} P_{c t}$ reflect the residuals estimated after regressing Satisfaction $_{c t}$ and $\ln (G D P)_{c t}$ (respectively) on country and wave fixed effects. Data are aggregated by first standardizing individual-level data to have mean zero and unit standard deviation, and then taking country-year averages of the standardized values. The dashed line gives the OLS fit and the dotted line is fitted from lowess regression. For further details, see text. 
Figure 12: Happiness and GDP: World Values Survey, 1999-2004

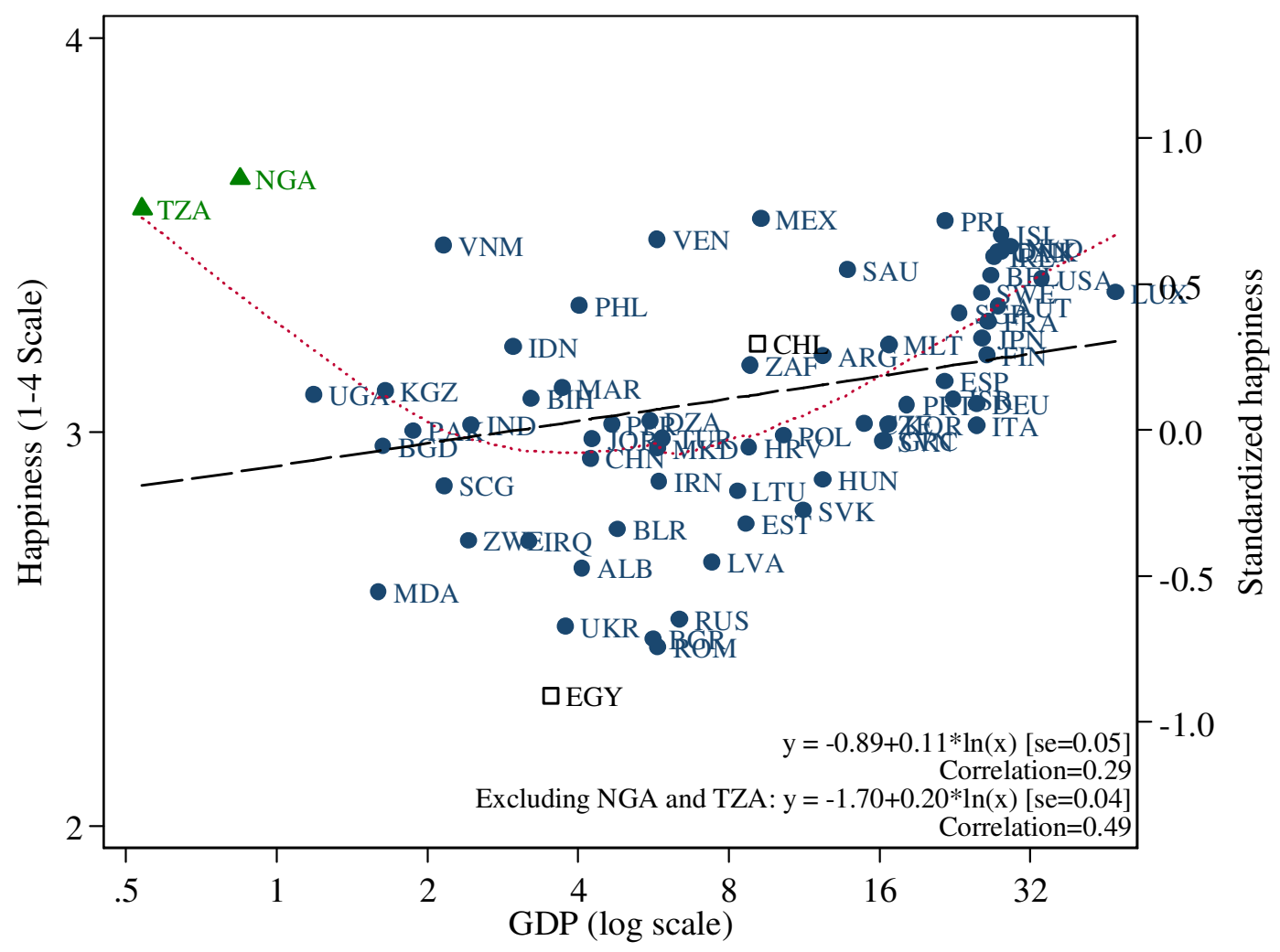

Notes: World Values Survey, 1999-2004, and author's regressions. Sources for GDP per capita are described in the text. The happiness question asks, "Taking all things together, would you say you are: 'very happy,' 'quite happy,' 'not very happy,' [or] 'not at all happy'?" Data are aggregated into country averages by first standardizing individual level data to have mean zero and standard deviation one, and then taking the within-country average of individual happiness. The dashed line plots fitted values from the reported OLS regression (including TZA and NGA); the dotted line gives fitted values from a lowess regressions. The regression coefficients are on the standardized scale. Both regressions are based on nationally representative samples. Observations represented by hollow squares are drawn from countries in which the World Values Survey sample is not nationally representative; see Stevenson and Wolfers (2008), appendix B, for further details. Sample includes sixty-nine developed and developing countries. 
Figure 13: Cross-Country Measures of Recalled Feelings and GDP, Gallup World Poll
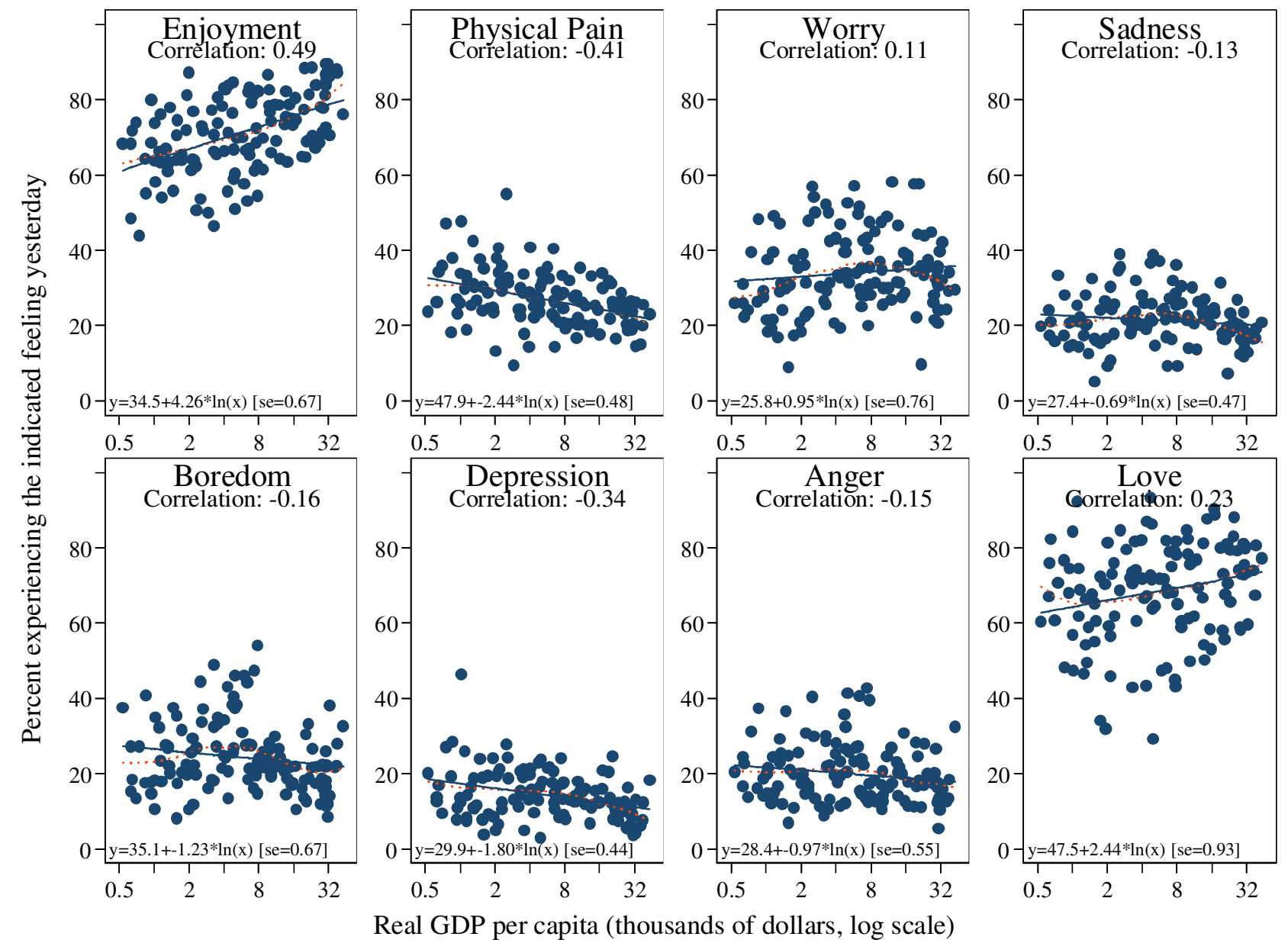

Notes: Gallup World Poll, 2006. Sources for GDP per capita described in the text. Respondents were asked, "Did you experience [feeling] during a lot of the day yesterday?" GDP per capita is at purchasing power parity in constant 2000 international dollars. Each observation represents one of up to 130 developed and developing countries in the sample (questions were not asked in Iraq). Dashed lines are fitted from ordinary least squares regressions of the percent agreeing with the statement on log real GDP per capita; dotted lines are fitted from lowess estimations. 
Figure 14: Cross-Country Measures of Daily Experience and GDP, Gallup World Poll
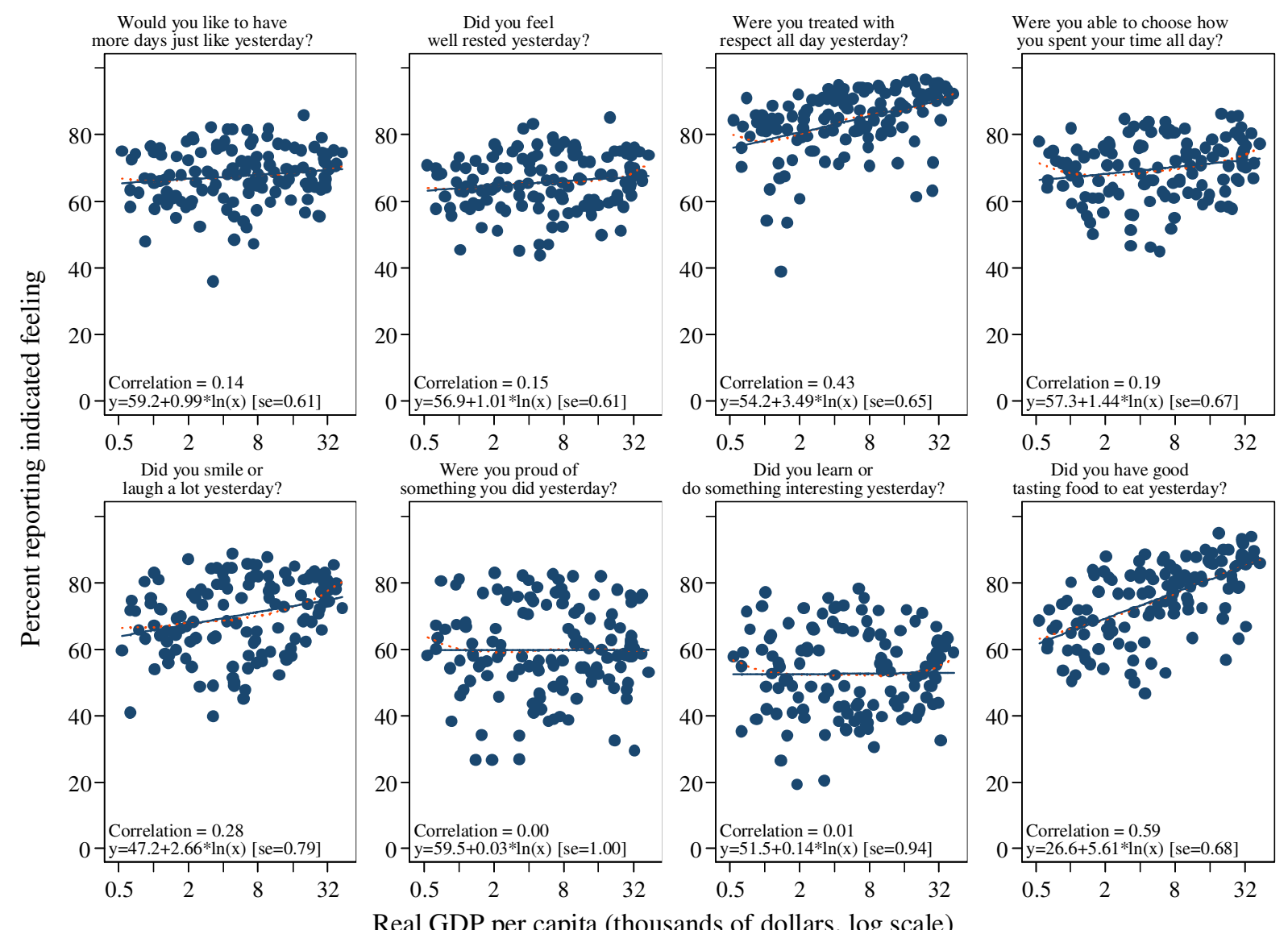

Notes: Gallup World Poll, 2006. Sources for GDP per capita described in the text. Questions were prefaced as follows: "Now, please think about yesterday, from the morning until the end of the day. Think about where you were, what you were doing, who you were with, and how you felt." Each observation represents one of up to 130 developed and developing countries in the sample (questions were not asked in Iraq). Dashed lines are fitted from OLS regressions of the percent agreeing with the statement on log real GDP per capita; dotted lines are fitted from lowess estimations. GDP per capita is at purchasing power parity in constant 2000 international dollars. 